\title{
Francesco Stancaros Schrift "Collatio doctrinae Arrii et Philippi Melanchthonis et sequacium": Kontextualisierung und Edition
}

Steiniger, Judith

DOI: https://doi.org/10.14315/arg-2019-1100106

Posted at the Zurich Open Repository and Archive, University of Zurich ZORA URL: https://doi.org/10.5167/uzh-190029

Journal Article

Published Version

Originally published at:

Steiniger, Judith (2019). Francesco Stancaros Schrift "Collatio doctrinae Arrii et Philippi Melanchthonis et sequacium": Kontextualisierung und Edition. Archiv für Reformationsgeschichte, 110(1):94-137.

DOI: https://doi.org/10.14315/arg-2019-1100106 


\title{
Francesco Stancaros Schrift „Collatio doctrinae Arrii et Philippi Melanchthonis et sequacium“: Kontextualisierung und Edition*
}

\author{
Von Judith Steiniger
}

\section{VORBEMERKUNG}

Der Reformator Heinrich Bullinger (geb. 1504 in Bremgarten, gest. 1575 in Zürich) war der Nachfolger Huldrych Zwinglis als Vorsteher der reformierten Gemeinde in Zürich und hinterließ eine Korrespondenz, die mit etwa 12.000 erhalten gebliebenen Stücken als umfangreichste aus dem 16. Jahrhundert gilt. Zum Vergleich: Der überlieferte Briefwechsel Zwinglis umfasst etwa 1.300 Stücke, derjenige Johannes Calvins sowie derjenige Martin Luthers etwa 4.200 bzw. 4.300, derjenige Philipp Melanchthons etwas mehr als 9.700 Briefe. ${ }^{1}$ Die zumeist auf Latein und Frühneuhochdeutsch verfassten Schreiben von und an Bullinger werden seit Ende der 1960er Jahre, zum Teil auf der Basis früherer Vorarbeiten, am Institut für Schweizerische Reformationsgeschichte an der Theologischen Fakultät der Universität Zürich erfasst, transkribiert und zusam-

* Für die freundliche, hilfreiche Begleitung meiner Arbeit an diesem Beitrag danke ich meinen Kollegen an der Heinrich-Bullinger-Briefwechseledition, Frau Dr. Alexandra Kess und Herrn PD Dr. Reinhard Bodenmann. - Im Folgenden verwendete Siglen und Abkürzungen: CO: Ioannis Calvini Opera quae supersunt omnia, hg. v. Wilhelm Baum, Eduard Cunitz, Eduard Reuß, Braunschweig 1863-Berlin 1900; CR: Philippi Melanthonis opera quae supersunt omnia, hg. v. Karl Gottlieb Bretschneider, Heinrich Ernst Bindseil, Halle a. d. Saale 1834-Braunschweig 1860; HBBW: Heinrich Bullinger Briefwechsel (wie Anm. 2); MBW: Melanchthons Briefwechsel, Kritische und kommentierte Gesamtausgabe, begründet von Heinz Scheible, im Auftrag der Heidelberger Akademie der Wissenschaften hg. v. Christine Mundhenk, Bd. 1ff., Stuttgart-Bad Cannstatt 1977ff.; Melanchthon-Bibliographie: Helmut Claus, Melanchthon-Bibliographie 1510 1560. Teilbd. 1: 1510-1540; Teilbd. 2: 1541-1550; Teilbd. 3: 1551-1560; Teilbd. 4: Register, Heidelberg 2014; VD 16: Verzeichnis der im deutschen Sprachbereich erschienenen Drucke des 16. Jahrhunderts (Onlinefassung).

1. Vgl. Traugott Schieß, Der Briefwechsel Heinrich Bullingers, in: Zwingliana 5/7 (1932), 396408; Fritz Büsser, Wurzeln der Reformation in Zürich. Zum 500. Geburtstag des Reformators Huldrych Zwingli, Leiden 1985, 126; sowie die Angabe zu Melanchthons Briefwechsel unter dem folgenden Link: http:/www.haw.uni-heidelberg.de/forschung/forschungsstellen/melanchthon/ geschichte.de.html (letztes Abrufdatum: 01.02.2018). 
men mit erklärenden Anmerkungen und jeweils einer ausführlichen deutschen Zusammenfassung in einer gedruckten Ausgabe veröffentlicht, die kurz HBBW genannt wird. Bisher sind 19 Bände und ein Ergänzungsband (10A) herausgegeben worden. ${ }^{2}$ Zudem wird jeder publizierte Band zwei Jahre nach seinem Erscheinen dem interessierten Publikum auch in einer elektronischen Ausgabe ${ }^{3}$ im Internet frei zugänglich gemacht, so dass auch kombinierte Recherchen in dem Briefkorpus möglich sind.

Während wir - Reinhard Bodenmann, Alexandra Kess und Judith Steiniger - an den Briefen arbeiteten, die aus Herbst 1546 und Winter 1546/1547 erhalten geblieben und inzwischen in den Bänden 18 (Briefe von Oktober bis Dezember 1546) und 19 (Briefe von Januar bis März 1547) publiziert sind, hat Reinhard Bodenmann einige Recherchen im Zusammenhang mit Erwähnungen des italienischen Theologen und Glaubensflüchtlings Francesco Stancaro angestellt, die für die Lösung von Datierungsfragen notwendig waren. Die Beschäftigung mit Stancaros Leben und die Tatsache, dass dessen Bewegungen nur spärlich dokumentiert sind, bewogen ihn dazu, für Band 19 der Ausgabe von Bullingers Briefwechsel eine neue biographische Notiz über den Mantuaner Theologen zu verfassen. ${ }^{4}$ Während seiner Forschungen stieß Reinhard Bodenmann auch auf das einzige erhalten gebliebene Exemplar von Stancaros Schrift "Collatio doctrinae Arrii et Philippi Melanchthonis et sequacium“ gegen Philipp Melanchthon und den ungarischen Theologen Franz Davidis (Ferenc Dávid) aus dem Jahr 1559, welches heute im Staatsarchiv Zürich (Signatur: E II 371, f. 748r.-757v.) aufbewahrt wird.

Da diese Schrift Stancaros und ihr Verbleib heute nicht mehr rezipiert werden, ${ }^{5}$ wird sie im vorliegenden Beitrag ediert. Der Edition vorangestellt sind zunächst einige einleitende Bemerkungen, die auf unsere Arbeit an Bullingers Briefwechsel zurückgehen und neue Details zu Stancaros Biographie in der Zeit von Winter 1546/1547 bis Anfang Mai 1547 liefern. Es folgen Ausführun-

2. Heinrich Bullinger Werke, Zweite Abteilung, Briefwechsel, im Auftrag des Zwinglivereins Zürich hg. vom Institut für Schweizerische Reformationsgeschichte mit Unterstützung des Schweizerischen Nationalfonds zur Förderung der wissenschaftlichen Forschung und der Reformierten Landeskirche des Kantons Zürich, Bde. 1ff., Zürich 1973ff.

3. http://teoirgsed.uzh.ch/ (letztes Abrufdatum: 30.09.2019).

4. HBBW 19, 271f., Anm. 9.

5. So wird diese Schrift zum Beispiel nicht erwähnt in der gehaltvollen Studie von Beate Kobler, Die Entstehung des negativen Melanchthonbildes. Protestantische Melanchthonkritik bis 1560, Tübingen 2015. Zu älteren Erwähnungen der Schrift in der Sekundärliteratur siehe unten Abschnitt IV. 
gen zur Druckgeschichte der "Collatio doctrinae“ und zu Erwähnungen dieser Schrift in der (älteren) Literatur bzw. in Bibliographien. In den Vorbemerkungen zur Edition findet sich dann ein kurzer Überblick über den Aufbau von Stancaros Schrift. Daran schließen sich einige Bemerkungen zur Edition und zu den Transkriptionsregeln an, denen ich bei der Erstellung des Textes gefolgt bin. Nach der Edition des Textes werden in einem Anhang die von ihm benutzten, in seiner Schrift erwähnten Quellen angeführt, soweit ich sie ermitteln konnte.

Auf eine Kommentierung der Streitschrift wird verzichtet. Diese und weitere Untersuchungen seien der künftigen Forschung vorbehalten.

\section{FRANCESCO STANCARO IN AUGSBURG UND BASEL}

Francesco Stancaro, geboren um 1501 in Mantua (Italien), gestorben am 12. November 1574 in Stopnica (Polen), ging als streitbare, immer wieder in Auseinandersetzungen verwickelte Persönlichkeit ${ }^{6}$ in die Kirchengeschichte ein. Er war Hebraist und Theologe; bisweilen wird erwähnt, dass er auch als Arzt tätig war. ${ }^{7}$ Über seine Herkunft ist nichts Näheres bekannt. Mitunter wird in der Forschungsliteratur vermutet, dass er aus einer jüdischen Familie stammte. ${ }^{8}$ Diese Annahme dürfte auf entsprechende, allerdings diskreditierende Äußerungen einiger seiner Zeitgenossen zurückgehen: In einem Briefzeugnis von Francesco Lismanini an Heinrich Bullinger vom 20. Oktober/3. November 1560

6. Man nannte ihn etwa einen „theologischen Condottiere und kampffrohen Streithahn in allen dogmatischen Auseinandersetzungen“; siehe Peter Bietenholz, Der italienische Humanismus und die Blütezeit des Buchdrucks in Basel, Basel 1959, 28. Vgl. ferner Erhard Peschke, „Stancarus, Franciscus“, in: Die Religion in Geschichte und Gegenwart, Bd. 6, 3. Auf., Tübingen 1962, Sp. 331.

7. So etwa in: Johannes Hallervorden, Bibliotheca curiosa, in qua plurimi rarissimi atque paucis cogniti scriptores [...] indicantur, Königsberg, Frankfurt 1676, 90 („Franciscus Stancarus Mantuanus Joannis Sepusii [= Zapolya] Principis Transylvaniae Medicus"); Erich Roth, Die Reformation in Siebenbürgen. Ihr Verhältnis zu Wittenberg und der Schweiz, Teil 2, Köln, Graz 1964, 20; Jan-Andrea Bernhard, Konsolidierung des reformierten Bekenntnisses im Reich der Stephanskrone. Ein Beitrag zur Kommunikationsgeschichte zwischen Ungarn und der Schweiz in der frühen Neuzeit (1500-1700), Göttingen, Bristol (Connecticut) 2015, 272f., wo Stancaro als Arzt bei Péter Petrović, dem Nachfolger Georg Martinuzzis, erwähnt wird.

8. Siehe beispielsweise Bietenholz, Italienischer Humanismus (wie Anm. 6), 56; George Huntston Williams, The Radical Reformation, 3. Aufl., Kirksville (Missouri) 1992, 854; Wactaw Urban, „Stancaro, Francesco d. Ä.“, in: Theologische Realenzyklopädie, Bd. 32, Berlin, New York 2001, 110; Joanna Kostyto, Commonwealth of all Faiths. Republican Myth and the Italian Diaspora in Sixteenth-Century Poland-Lithuania, in: Karin Friedrich, Barbara M. Pendzich, Hg., Citizenship and Identity in a Multinational Commonwealth. Poland-Lithuania in Context, 1550-1772, Leiden, Boston 2009, 190. 
wird Stancaro als hunc miserum Judaeum bezeichnet. ${ }^{9}$ Stancaro wies dies zurück. Er klagte im Jahr 1562 über dergleichen Verleumdungen (mendaciis) seiner Gegner, die ihn unter anderem Iudaeum circumcisum nennen würden. ${ }^{10}$ Im Jahr 1530 veröffentlichte er in Venedig ein Lehrbuch des Hebräischen. ${ }^{11}$ Später soll er in ein Kloster eingetreten und Priester geworden sein. ${ }^{12}$ Um 1540 war er in Padua als Sprachlehrer tätig, wandte sich der Reformation zu, publizierte einige heute nicht mehr bekannte Schriften gegen die Missbräuche in der katholischen Kirche und wurde in Mantua, dann auch in Venedig inhaftiert. Dies berichtet Stancaro selbst, und zwar in seiner Lebensbeschreibung in Form eines Briefes, den er viele Jahre später an den Grafen Andreas (Andrzej) von Górka ${ }^{13}$ richtete. ${ }^{14}$ Dieser Brief Stancaros mit seiner Vita wurde als Beilage zu einem Brief von Górka an Herzog Albrecht von Preußen vom 26. Januar 1551 mitgeschickt. ${ }^{15}$ Somit könnte Stancaro diese Biographie vielleicht Ende 1550 oder Anfang 1551 niedergeschrieben haben. Seine Selbstdarstellung entspricht übrigens nicht ganz den Tatsachen und hat als chronologische Quelle keinen großen Wert, denn Stancaro hat darin zum Beispiel seine Aufenthalte in Wien (1545/46) und in Basel (1547) - dazu weiter unten im vorliegenden Beitrag mit keinem Wort erwähnt.

Nach einer (wie er in dem eben genannten Brief selbst berichtet) „wundersamen "Befreiung aus dem Gefängnis ${ }^{16}$ hielt er sich noch für einige Zeit in Venedig auf ${ }^{17}$ und heiratete dort. Seine Frau hieß Magdalene, stammte aus Piur in der Nähe von Chiavenna (im Untertanengebiet der Drei Bünde) und soll in

9. Siehe Theodor Wotschke, Der Briefwechsel der Schweizer mit den Polen, Leipzig 1908, 117.

10. Siehe Wotschke, Briefwechsel (wie Anm. 9), 156, Anm. 2; Theodor Wotschke, „Francesco Stancaro“, in: Altpreußische Monatsschrift 47 (1910), 465-498, 570-613 (hier 473 und 477); sowie Agostino Mainardi aus Chiavenna an Heinrich Bullinger vom 22. September 1548 (Bericht über einen Brief Domenico Manzonis aus Venedig), in: Bullingers Korrespondenz mit den Graubündnern, 1. Teil: Januar 1533-April 1557, hg. v. Traugott Schieß, Basel 1904, 135.

11. De modo legendi Hebraice institutio brevissima, Venedig 1530; siehe Christian August Salig, Vollständige Historie Der Augspurgischen Confession und derselben zugethanen Kirchen, Teil 2, Halle 1733, 716.

12. Siehe Wotschke, „Stancaro“ (wie Anm. 10), 466.

13. Gestorben am 3. Dezember 1551; siehe MBW Bd. 12, Personen F-K, bearbeitet von Heinz Scheible unter Mitwirkung von Corinna Schneider, Stuttgart-Bad Cannstatt 2005, 166f. (mit weiterer Literatur).

14. Gedruckt in: Wotschke, „Stancaro“ (wie Anm. 10), 589-592 (Beilage I).

15. Siehe Martin Stupperich, Osiander in Preußen 1549-1552, Berlin, New York 1973, 166 mit Anm. 3f.

16. Siehe Wotschke, „Stancaro“ (wie Anm. 10), 589: „unde mirabilibus modis et stupendis mediis liberatus".

17. Siehe dazu ebd., 466 . 
schlechtem Ruf gestanden haben. Vermutlich ließ Stancaro sich bald von ihr scheiden (später, in Polen, heiratete er ein zweites Mal; seine zweite Frau stammte aus der protestantischen Pastorenfamilie Łós und trug denselben Vornamen wie die erste). ${ }^{18}$ Dann floh er aus Italien nach Chiavenna, wo er 1543 nachgewiesen ist. ${ }^{19}$ Im Frühling oder Sommer des Jahres 1545 (nicht 1544) ${ }^{20}$ immatrikulierte er sich an der Universität in Wien und erhielt im Oktober den dortigen Lehrstuhl für Hebräisch, der im Jahr 1535 von König Ferdinand I. eingerichtet worden war. ${ }^{21}$ Aufgrund von kritischen Äußerungen Stancaros über die römische Kirche wurde ein inquisitorisches Verfahren gegen ihn angestrengt, in dessen Folge König Ferdinand unter dem 30. März 1546 seine Entfernung anordnete. ${ }^{22}$

Stancaro kam dieser Vertreibung zuvor, indem er schon kurz vor dem 5. Februar 1546 in Regensburg erschien, wo vom 27. Januar bis zum 20. März 1546 das Zweite Regensburger Religionsgespräch stattfand. Gewiss erhoffte er sich, dort neue Kontakte knüpfen zu können. Seine Bemühungen waren erfolgreich. Die Auditoren und Kollokutoren sammelten am 14. März 1546 Geld für ihn, ${ }^{23}$ und nach dem 17. März 1546 reiste Stancaro aus Regensburg ab. Er wandte sich nach Augsburg, ${ }^{24}$ wo er durch die Vermittlung des ebenfalls aus Italien geflohenen ehemaligen Kapuzinermönchs Bernardino Ochino, der seit Spätsommer 1545 in Augsburg als Prediger wirkte, ${ }^{25}$ ein Lehramt für Griechisch und Hebräisch antreten konnte. Vom dortigen Rat wurde er (soweit in den Akten belegt ist) zweimal finanziell unterstützt. ${ }^{26}$ Zudem half Stancaro dem Augsburger Stadtarzt Gereon Sailer, ${ }^{27}$ Schriften aus dem Umfeld des

18. Siehe Urban, „Stancaro“ (wie Anm. 8), 110.

19. Siehe HBBW 19, 271, Anm. 9. - Vermutlich kam Stancaro damals auch nach Chur, denn Johannes Comander schrieb im Juni 1548 an Bullinger, dass er Stancaro seit 14 Jahren kenne; siehe Schieß, Bullingers Korrespondenz mit den Graubündnern (wie Anm. 10), 126 (Teil 2 von Nr. 97).

20. Die Matrikel der Universität Wien, Bd. 3, 1518/II-1579/I, bearbeitet von Franz Gall, Willy Svaizert, Wien, Köln, Graz 1971, 75 sowie HBBW 18, 309, Anm. 72 . - Das Jahr 1544 ist angegeben bei Francesco Ruffini, Studi sui riformatori italiani, Turin 1955, 174.

21. Siehe dazu Wotschke, „Stancaro“ (wie Anm. 10), 467 mit Anm. 2.

22. Siehe dazu HBBW 19, 381, Anm. 17, mit Bezug auf Joseph Ritter von Aschbach, Die Wiener Universität und ihre Gelehrten 1520 bis 1565, Wien 1888, 92.

23. Siehe Victor Schultze, Das Tagebuch des Grafen Wolrad II. zu Waldeck zum Regensburger Religionsgespräch 1546, Teil II, in: Archiv für Reformationsgeschichte 7 (1909/1910), 333.

24. Siehe HBBW 18, 280, Anm. 6, sowie Friedrich Roth, Augsburgs Reformationsgeschichte, Bd. 3, 1539-1547 bzw. 1548, München 1907, 244.

25. Siehe dazu Judith Steiniger, Eine unbekannte Schrift von Bernardino Ochino, in: Zwingliana 43 (2016), 133f.

26. Siehe Roth, Reformationsgeschichte (wie Anm. 24), 244 mit Anm. 43 und 44.

27. Zu ihm siehe Wilhelm Vogt, „Sayler, Gereon“, in: Allgemeine Deutsche Biographie 30 (1890), 462-464. 
Schmalkaldischen Krieges ins Italienische zu übersetzen, die dieser im Auftrag des Rates auf „teutsch und welsch“ ${ }^{28}$ (also auf Deutsch und Italienisch) drucken ließ. Stancaro trat in Augsburg auch in Kontakt zu dem Stadtschreiber Georg Frölich und zu dem aus Zürich berufenen jungen Pfarrer Johannes Haller. ${ }^{29} \mathrm{Als}$ Heinrich Bullinger ein Buchgeschenk an Stancaro in Augsburg übersandte, ließ dieser in einem Brief Hallers seinen Dank an Bullinger ausrichten; ${ }^{30}$ und mit einem weiteren Brief Hallers vom 7. Januar 1547 ließ Stancaro - der sich zu dieser Zeit womöglich schon nicht mehr in Augsburg befand - durch Haller zwei nicht näher bekannte Schriften als Gegengabe an den Zürcher Gemeindevorsteher senden. ${ }^{31}$

Inzwischen hatte nach dem Donaufeldzug des Kaisers Karl V. gegen die deutschen Protestanten (Juli-November 1546) zunächst die Stadt Ulm, wo sich der Sitz des Schmalkaldischen Bundes befand, im Dezember 1546 vor Karl V. kapituliert. ${ }^{32}$ Dem Beispiel Ulms folgten die Städte Biberach, Isny, Kempten, Memmingen und Ravensburg, die sich dem Kaiser am 16. Januar 1547 in Heilbronn zu Füßen warfen. Auch der Augsburger Große Rat beschloss, in Friedensverhandlungen mit Karl einzutreten. ${ }^{33}$ Am 24. Januar zeigte sich der Rat bereit zur bedingungslosen Unterwerfung, und schon wenige Tage später, am 29. Januar, vollzogen die Augsburger Gesandten den Fußfall in Ulm. ${ }^{34}$ Währenddessen wurde weiter über die Friedensbedingungen verhandelt, insbesondere über die Höhe der Entschädigung. ${ }^{35} \mathrm{Zu}$ den Forderungen des Kaisers an die Stadt gehörte aber nicht nur die Erlegung einer Geldstrafe und die Aufnahme einer kaiserlichen Besatzung, sondern auch die Auslieferung des schmalkaldischen Truppenführers Sebastian Schertlin und des Predigers Bernardino

28. Gereon Sailer an Landgraf Philipp von Hessen, 18. September 1546, gedruckt in: Briefwechsel Landgraf Philipp's des Großmüthigen von Hessen mit Bucer, hg. und erläutert von Max Lenz, Bd. 3, Leipzig 1891, 455f., Nachschrift auf S. 456 (die Titel der Schriften ebd. in Anm. 1); Roth, Reformationsgeschichte (wie Anm. 24), 244 und Anm. 42.

29. Siehe Johannes Haller an Bullinger, 15. November 1546, in: HBBW 18, 277,[1] und 279, Zeilen 2-5; derselbe an denselben, 20. November 1546, ebd., 304,[9] und 308f., Zeilen 103-107.

30. Siehe Johannes Haller an Bullinger, 23. Dezember 1546, in: HBBW 18, 430,[9] und 434, Zeilen 92-94. Bei der Schrift handelte es sich wohl um die „Orthodoxa Tigurinae ecclesiae ministrorum confessio"; siehe HBBW 18, 434, Anm. 62.

31. Siehe HBBW 19, 95,[12] und 98, Anm. 31.

32. Siehe dazu HBBW 19, 72, Anm. 4.

33. Siehe HBBW 18, 431, Zeilen 9-16 und 28-30; sowie HBBW 19, 87, Zeile 9-11; 149, Zeilen 6-11.

34. Siehe HBBW 19, 188, Anm. 7 und 12.

35. Siehe HBBW 19, 188, Anm. 7. 
Ochino, ${ }^{36}$ der Stancaro im Jahr zuvor nach Augsburg geholt hatte. Diesem kaiser-lichen Auslieferungsbegehren kamen - in Übereinkunft mit den Augsburger Stadtbehörden - sowohl Ochino als auch Schertlin zuvor, indem sie die Stadt heimlich verließen. Während Ochino, begleitet von einer Augsburger Leibwache, spätestens am 25. Januar 1547 wegzog, am Abend des 29. Januars in Konstanz eintraf ${ }^{37}$ und sich von dort weiter nach Zürich (ca. 2. Februar) und Basel (4./5. Februar) wandte, ${ }^{38}$ zog Schertlin erst einige Tage später, am 29. Januar 1547, aus der Stadt am Lech und begab sich über Lindau nach Konstanz. ${ }^{39}$

Auch Stancaro verließ Augsburg. Als Johannes Haller den oben erwähnten Brief an Bullinger vom 7. Januar 1547 schrieb, wusste er noch nicht, dass Stancaro weggehen würde oder schon weggegangen war. Das heißt aber nicht, dass Stancaro Augsburg noch nicht verlassen haben konnte. Vielmehr scheint er am 7. Januar bereits auf der Reise nach Basel gewesen zu sein oder unmittelbar vor der Abreise gestanden zu haben. Der kürzeste Weg zwischen Augsburg und Basel beträgt um die 300 Kilometer, das entsprach einer Reisezeit von ungefähr 10 Tagen, wenn nicht mehr. Vermutlich wird Stancaro das Kriegsgebiet umgangen und einen Umweg über Stuttgart und Straßburg genommen haben (etwa 400 $\mathrm{km})$. Fest steht, dass, als zwischen dem 15. und 19. Januar der Basler Pfarrer Johannes Gast seinen Brief an Bullinger verfasste, Stancaro bereits vor „einigen Tagen" in Basel angekommen war. ${ }^{40}$ Der zuletzt bezeugte (und auch erhaltene) Brief von Haller an Bullinger stammt vom 27. Dezember 1546. ${ }^{41}$ Da Haller mit diesem Brief noch nicht die Büchlein von Stancaro übermittelte, wird er diese frühestens am 27. Dezember erhalten haben. Stancaro wird also Augsburg zwischen dem 27. Dezember 1546 und ca. dem 7. Januar 1547 verlassen haben, ohne Haller etwas davon gesagt zu haben. Vielleicht wusste er zum Zeitpunkt der Bücherübergabe noch nichts von der guten Gelegenheit, die sich ihm damals angeboten haben wird, um die Reise nach Basel sicher zu unternehmen. Auch am 1. Februar 1547 scheint Haller noch nichts Genaueres über die Umstände von Stancaros Abreise gewusst zu haben. Er schreibt lediglich, dass der Augsburger Rat Ochino und Stancaro verabschiedet hätte (was allerdings nicht

36. Siehe HBBW 19, 188, Zeilen 10f.; 243, Zeilen 8f.

37. Siehe HBBW 19, 188f, Anm. 17.

38. Siehe HBBW 19, 233, Anm. 14.

39. Siehe HBBW 19, 189, Anm. 18.

40. HBBW 19, Nr. 2753.

41. HBBW 18, Nr. 2726. 
bedeutet, dass sie gemeinsam verabschiedet wurden $)^{42}$ - eine Stelle, die spätere Historiker ${ }^{43}$ dazu verleitet haben wird, von einer gemeinsamen Abreise Stancaros und Ochinos aus Augsburg zu sprechen. Am 3. Februar wusste Haller immer noch nicht, was genau mit Ochino und Stancaro passiert war. ${ }^{44}$ Dass es aber nicht zu dieser gemeinsamen Abreise kam, geht nun klar aus dem oben erwähnten Brief von Johannes Gast an Bullinger hervor.

Dass Stancaro Augsburg nicht erst kurz vor dem 1. Februar verlassen haben kann, geht zudem auch aus folgender Beobachtung hervor. Am 7. Februar bedankte sich Stancaro mit einem Brief an Bullinger für einen heute nicht mehr erhaltenen Brief des Letzteren, in dem dieser Stancaro mitteilte, dass er für ihn eine Stelle im Berner Gebiet suchte. ${ }^{45}$ Dies setzt wiederum voraus, dass Bullinger von Stancaros Anwesenheit in Basel gehört hatte. Angesichts der Distanz von etwa 80 Kilometern zwischen Basel und Zürich heißt das, dass die Nachricht von Stancaros Ankunft in Basel spätestens am 2. Februar von Basel ausgegangen sein muss, da man für ihre Übermittlung mit etwa zwei bis drei Tagen rechnen muss, und man wiederum zwei bis drei Tage hinzurechnen muss für die Übermittlung von Bullingers Brief nach Basel, den Stancaro dann am 7. Februar beantwortete. Doch eine Ankunft Stancaros in Basel erst um den 2. Februar würde bedeuten, dass er Augsburg spätestens um den 22. Januar verlassen hat.

Dass Ochino und Stancaro nicht zusammen von Augsburg in die Eidgenossenschaft gereist sind, geht auch deutlich aus den in HBBW, Band 19, veröffentlichten Briefen hervor. Ochino hatte, wie oben schon bemerkt, Augsburg spätestens am 25. Januar verlassen und traf ohne Stancaro am Abend des 29. Januar in Konstanz ein, ist am 31. Januar noch in St. Gallen nachgewiesen und reiste am 2. Februar (ohne sich dort länger aufzuhalten) ohne Stancaro durch Zürich, so dass seine Ankunft in Basel auf den 4. oder 5. Februar anzusetzen ist. ${ }^{46}$

Diese neuen Erkenntnisse geben Anlass, den schon von Stancaro selbst und

42. HBBW 19, Nr. 2786.

43. Siehe etwa Friedrich Trechsel, Die Protestantischen Antitrinitarier vor Faustus Socin nach Quellen und Urkunden geschichtlich dargestellt, Bd. 2: Lelio Sozini und die Antitrinitarier seiner Zeit, Heidelberg 1844, 209; Roth, Reformationsgeschichte (wie Anm. 24), 473; Karl Benrath, Bernardino Ochino von Siena. Ein Beitrag zur Geschichte der Reformation, 2. Aufl., Braunschweig 1892, 170; Barbara Sher Tinsley, Pierre Bayle's Reformation. Conscience and Criticism on the Eve of the Enlightenment, Selinsgrove, London 2001, 286; Mark Taplin, The Italian Reformers and the Zurich Church, c. 1540-1620, Aldershot 2003, 35.

44. HBBW 19, Nr. 2791.

45. HBBW 19, Nr. 2799.

46. HBBW 19, 225 und Anm. 47; 226; 233, Anm. 14; 241. 
einigen Zeitgenossen angeführten Grund von Stancaros Weggang aus Augsburg infrage zu stellen: Er hätte Augsburg verlassen, weil er sich vor dem Kaiser und vor König Ferdinand I. gefürchtet hätte (so Stancaros Erklärungen in Basel) ${ }^{47}$, ja sogar (so Haller) ${ }^{48}$ weil dessen Auslieferung wie jene Ochinos vom Kaiser gefordert worden wäre. Letztere Aussage kann allerdings nicht stimmen, denn wie wäre dann zu erklären, dass Stancaro sich spätestens am 2. Mai von Basel erneut nach Augsburg begab, ${ }^{49}$ welches sich unterdessen (wie oben schon bemerkt) am 29. Januar ${ }^{50}$ dem Kaiser unterworfen hatte und seit dem 21. Februar ${ }^{51}$ von kaiserlichen Truppen besetzt war?

Vielmehr ist aus der Tatsache, dass Stancaro zwischen Januar und April zahlreiche Schriften in Basel drucken ließ, ehe er wieder nach Augsburg zog, der Schluss erlaubt, dass Stancaro, der wohl Angst vor König Ferdinand I. hatte, da dieser seine Absetzung an der Universität zu Wien veranlasst hatte, ${ }^{52}$ sich hauptsächlich deshalb nach Basel begeben haben wird, weil er dort seine Schriften drucken lassen wollte, die von Augsburg aus (wenn sie dort gedruckt worden wären) längst nicht so leicht nach Italien hätten befördert werden können!

Demzufolge ist Stancaro gewiss nicht aus Furcht vor dem Kaiser aus Augsburg geflohen, sondern um seine Arbeiten in Basel drucken und bis nach Italien verbreiten zu lassen. Die Buchdrucker in der Stadt am Rheinknie pflegten ausgezeichnete Beziehungen zum italienischen Buchmarkt, was auch in Bullingers Briefwechsel belegt ist. ${ }^{53}$ Tatsächlich sind im „Verzeichnis der im deutschen Sprachbereich erschienenen Drucke des 16. Jahrhunderts (VD 16)“ nicht weniger als sieben Titel aus Stancaros Feder aufgeführt, die in der ersten Hälfte des Jahres 1547 in Basel publiziert wurden - allein vier davon im Monat April, während Stancaro sich noch in Basel aufhielt; die anderen wurden ebenda offenbar nach seinem Weggang gedruckt, ${ }^{54}$ der kurz vor dem

\footnotetext{
47. HBBW 19, 126,[5].

48. HBBW 19, 233,[2].

49. HBBW 19, 271, Anm. 9.

50. HBBW 19, 235,[8].

51. HBBW 19, 254, Anm. 42; 338,[2]; 344,[20].

52. Siehe oben bei Anm. 22.
}

53. Siehe dazu HBBW 18, 47,[2] und 148, Zeile 7; ferner Bietenholz, Italienischer Humanismus (wie Anm. 6), passim, bes. 13f.; Verena Vetter, Baslerische Italienreisen vom ausgehenden Mittelalter bis in das 17. Jahrhundert, Diss. phil., Basel 1952, $50 \mathrm{f}$.

54. Opera nuova di Francesco Stancaro Mantoano della riformatione, si della dottrina Christiana (Basel: Johannes Oporinus, 1547; im Impressum auf dem Titelblatt ist der 1. April 1547 als Datum des Drucks angegeben; VD 16 S 8553); Ebreae grammaticae institutio (Basel: Jakob Kündig, 1547; VD 16 S 8551, auch: S 8549; die am Ende befindlichen elegischen Distichen sind auf den 9. April 1547 datiert); Yose Ben-Halafta, De decem captivitatibus Iudaeorum et 
2. Mai desselben Jahres erfolgte (mehr dazu weiter unten). Nie wieder erschienen so viele Titel von Stancaro, und in einem so kurzen Zeitraum. Er kann also nicht all diese Bücher erst während seines Aufenthalts in Basel geschrieben haben, sondern schon früher, in Wien und in Augsburg. Stancaro schrieb sich auch an der Basler Universität ein. ${ }^{55}$ Er habe dort "nach entsprechender Ausbildung den Doktor der Medizin" erworben, wie Wacław Urban notierte. ${ }^{56}$ Worauf diese Aussage beruht und ob sie stimmt, muss allerdings derzeit offengelassen werden.

Am 7. Februar 1547 hatte sich Stancaro (wie schon gesehen) aus Basel mit einem Brief an den Zürcher Antistes Heinrich Bullinger gewandt, ${ }^{57}$ aus welchem deutlich wird, dass Bullinger ihm bereits zuvor einen heute nicht mehr erhaltenen Brief geschrieben hatte, in dem er Stancaro informierte, dass er sich bei den Bernern um eine Stelle für ihn, den Glaubensflüchtling, bemühte. In Bern war die Stelle von Thomas Grynäus vakant geworden, ${ }^{58}$ und in Lausanne, das seit 1536 zum bernischen Einflussbereich gehörte, hatte man den (im Jahr 1542 ebenfalls aus Italien geflohenen) Celio Secondo Curione entlassen, ${ }^{59}$ der seinen Wohnsitz daraufhin nach Basel verlegt hatte und dort seit Januar 1547 den Lehrstuhl für Rhetorik innehatte. Bei Letzterem wohnte Stancaro während seines Basler Aufenthalts, wie ein Brief von Curione an Bullinger vom 8. Februar $1547^{60}$ bezeugt, in dem Curione seinen sprachbegabten Kollegen Stancaro für die Stelle eines Theologielehrers in Lausanne empfiehlt. ${ }^{61}$ Am 8. Februar 1547 richtete schließlich auch der Augsburger Stadtschreiber Georg Frölich die Bitte an Bullinger, Stancaro zu helfen, zumal dieser ein Buch über das Abendmahl verfasst habe und die gleiche

sanguine Zachariae (übersetzt von Stancaro; Basel: Jakob Kündig, 1547; VD 16 ZV 27925; die Vorrede des Druckers datiert vom 15. April 1547); Autentica testimonia fidei Christianae Hebraice (Basel: Jakob Kündig, 1547; VD 16 ZV 28062; die Vorrede des Druckers datiert vom 16. April 1547); Conciliatio Christi et Mosis de divortio (Basel: Jakob Kündig, VD 16 S 8544; die Vorrede des Druckers datiert vom 13. Juni 1547); Explanatio divi Iacobi a Thaddaeo Duno Locarniensi (Basel: Jakob Kündig, August 1547, VD 16 B 5217); Ispositione de la epistola canonica di S. Giacobo vescovo di Gierusaleme (bearbeitet von Stancaro; Basel: Johannes Oporinus, 1547; VD 16 ZV 23760; ohne weitere Datumsangabe). - Siehe auch Bietenholz, Italienischer Humanismus (wie Anm. 6), 28f.; Dennis E. Rhodes, Three Works of Heterodox Italian Authors printed at Basle, in: Gutenberg-Jahrbuch 74 (1999), 158-160.

55. Siehe Die Matrikel der Universität Basel, hg. v. Hans Georg Wackernagel unter Mitarbeit von Marc Sieber, Hans Sutter, Bd. 2 (1532/33-1600/01), Basel 1956, 47, Nr. 15.

56. Urban, „Stancaro“ (wie Anm. 8), 110.

57. HBBW 19, Nr. 2799.

58. Siehe dazu HBBW 19, 77, Anm. 12 und 270, Anm. 3.

59. Siehe dazu HBBW 19, Nr. 2735 mit Anm. 2 und 4.

60. HBBW 19, Nr. 2802.

61. Siehe HBBW 19, 281,[2] und 282, Zeilen 22-37. 
Meinung wie Bullinger in der Schrift „De sacramentis“ vertrete. ${ }^{62}$ Unter dem Datum des 4. März 1547 schickte Curione erneut ein Schreiben an Bullinger, ${ }^{63}$ um mitzuteilen, dass er und Stancaro weiterhin darauf warteten, von Bullinger zu erfahren, ob dessen Stellensuche für Stancaro erfolgreich war oder nicht. Aus einem Brief des ebenfalls in Basel lebenden Francisco de Enzinas vom 7. März ${ }^{64}$ wird ersichtlich, dass Bullinger das negative Ergebnis seiner Stellensuche nicht an Stancaro oder Curione direkt meldete, sondern Enzinas mitteilte, und zwar mit einem heute nicht mehr erhaltenen Brief, in dem er den Empfänger bat, dieses negative Ergebnis Stancaro schonend beizubringen.

Stancaros Aufenthalt in Basel währte nicht lange. Um Mitte Januar 1547 war er dort angekommen, und schon kurz vor dem 2. Mai desselben Jahres zog er wieder weiter, und zwar erstaunlicherweise zurück nach Augsburg, was (wie schon gesagt) darauf hinweist, dass er nicht aus Augsburg geflohen war. Von seiner Abreise aus Basel erfahren wir aus einem Brief, den Celio Secondo Curione aus Basel am 2. Mai 1547 an Bullinger schrieb. ${ }^{65}$ Darin heißt es auch, dass Stancaro gerne über Zürich gereist wäre, um Bullinger zu sehen, dass er sich jedoch zusammen mit einem Gefährten auf den Weg machte, welcher nicht über Zürich reisen wollte; daher lasse Stancaro die für Bullinger bestimmte hebräische Grammatik ${ }^{66}$ zurück, die er in Basel herausgegeben hatte und die Curione mit einem Gruß von Stancaro an Bullinger übermitteln solle. Curione vertraute seinen Brief und Stancaros Grammatik Caspar Herwagen an, einem Neffen des Basler Druckers Herwagen, ${ }^{67}$ der auf dem Weg nach Italien war, was aus einem Brief vom 27. August an Bullinger deutlich wird. ${ }^{68}$ Was bewog nun Stancaro dazu, sich ausgerechnet für Augsburg zu entscheiden? Wir wissen es nicht. Fest steht aber, dass er während seines Basler Aufenthaltes seine Kontakte nach Augsburg nicht hatte abreißen lassen, wie wir einem Brief Hallers an Bullinger vom 9. Februar 1547 entnehmen und aus dem hervorgeht, dass Haller an eben diesem Tag einen Brief von Stancaro aus Basel erhalten hatte. ${ }^{69}$

62. HBBW 19, 283,[3] und 284, Zeilen 11-17.

63. HBBW 19, Nr. 2836.

64. HBBW 19, Nr. 2840.

65. Siehe Celio Secondo Curione an Bullinger, 2. Mai 1547 (Signatur des Autographs: Zürich StA, E II 366, 81); vgl. auch HBBW 19, 271, Anm. 9.

66. Es handelt sich um die bereits oben in Anm. 54 angeführte Grammatik.

67. Siehe Die Amerbachkorrespondenz, 8. Bd.: Die Briefe aus den Jahren 1551 und 1552, hg. v. Beat Rudolf Jenny, Basel 1974, 143f. (zu Nr. 3479).

68. Siehe Zürich StA, E II 346, 211; Teildruck in CO XII 585, 943.

69. HBBW 19, 288,[9] und 290, Zeile 44. 
Aber auch dieser erneute Halt Stancaros in Augsburg sollte nicht von Dauer sein. Spätestens im Juni 1548 befand er sich abermals in Graubünden und war in einen Streit über die Sakramente in der Gemeinde von Chiavenna verwickelt. Er und Agostino Mainardi ließen sich mit einem Empfehlungsschreiben von Johannes Comander in Chur zu Bullinger und zu den Zürcher Theologen schicken, um diese um eine Entscheidung des Streites zu bitten. ${ }^{70}$ Für den weiteren Lebensweg Stancaros bis zum Druck seiner Schrift gegen Melanchthon im Jahr 1559 sei sowohl auf die Darstellungen von Theodor Wotschke in seinem Aufsatz über Stancaro ${ }^{71}$ und von Lorenz Hein in seinem Buch über den Einfluss der italienischen Protestanten auf die Reformation in Polen ${ }^{72}$ als auch auf die bereits erwähnte Notiz von Reinhard Bodenmann verwiesen.

\section{DIE DRUCKGESCHICHTE VON STANCAROS SCHRIFT „COL- LATIO DOCTRINAE“}

Von Anfang November 1554 bis zum Frühjahr 1559 lebte Stancaro an verschiedenen Orten in Ungarn-Siebenbürgen, unter anderem in Klausenburg (ungarisch: Koloszvár, rumänisch: Cluj, heute: Cluj-Napoca). Dort wandte sich im Jahr 1555 der Schulrektor Franz Davidis im Auftrag der lutherischen Gemeinde mit einer Schrift unter dem Titel „Dialysis scripti Stancari“73 gegen ihn. Er bekämpfte Stancaro als Nestorianer, ließ lutherische Synoden Beschlüsse gegen ihn fassen und hielt 1557 eine öffentliche Disputation in Klausenburg mit ihm ab, bei der Stancaro Melanchthon als Arianer bezeichnete „und später seine Thesen in Druck ausgehen ließ ${ }^{“ 74}$ - dies ist die Vorgeschichte des Druckes der „Collatio doctrinae“.

70. Johannes Comander an Bullinger, 1. Juni 1548, gedruckt in: Schieß, Bullingers Korrespondenz mit den Graubündnern (wie Anm. 10), 125-127, Nr. 97.

71. Siehe Anm. 10.

72. Lorenz Hein, Italienische Protestanten und ihr Einfluss auf die Reformation in Polen während der beiden Jahrzehnte vor dem Sandomirer Konsens (1570), Leiden 1974, 69-97.

73. Franz Davidis, Dialysis scripti Stancari contra primum articulum synodi Szekiensis, qui de doctrina controvertitur, conscripta per Franciscum Davidis, Claudiopoli (Koloszvár, Klausenburg, Cluj): [Georg] Hoffgreff, 1555; siehe Hein, Italienische Protestanten (wie Anm. 72), 82, Anm. 77. - Das einzige erhaltene Exemplar befindet sich im Budapester Nationalmuseum; siehe Roth, Reformation in Siebenbürgen (wie Anm. 7), 21, Anm. 5. Siehe auch den Online-Katalog „Nektár“ der National Széchényi Library (NSZL), Budapest, Ungarn.

74. Siehe den Artikel „David, Ferenc (Franz Davidis)“, in: Controversia et Confessio Digital, hg. v. Irene Dingel, http://www.controversia-et-confessio.de/id/f9bd643c-4762-41fdb3f2-a30946211064 (letztes Abrufdatum: 27.02.2018). 
Nach diesem fast fünfjährigen Aufenthalt in Ungarn-Siebenbürgen kehrte Stancaro im Mai 1559 nach Polen zurück, ${ }^{75}$ wo er schon früher, von 1549 bis $1551{ }^{76}$ gewesen war. Er wandte sich nach Pińczów (Woiwodschaft Heiligkreuz, Województwo świętokrzyskie). Der Grundherr dieses Städtchens, Nikolaus Olesnicki (Mikołaj Oleśnicki), hatte ihm bereits im Jahr 1550 Zuflucht gewährt. ${ }^{77}$ Zudem war Stancaro mit dem Rektor der dortigen evangelischen Schule, Gregor Orsatius (Grzegorz Orszak), befreundet. Kurz nach seiner Ankunft in Pińczów brachteder ruheloseStancaro im Verein mit Orsatius den Pińczówer Drucker Daniel aus Lenschitz (polnisch: Łęczyca; daher latinisiert „Lancisius") ${ }^{78}$ unter Umgehung der kirchlichen Zensur ${ }^{79}$ dazu, seine noch in Klausenburg verfassten Thesen gegen Melanchthon unter dem Titel „Collatio doctrinae [...]“ zu drucken. In älteren polnischen Bibliographien und in der Melanchthon-Bibliographie von Helmut Claus ist überdies zu finden, dass der Drucker Daniel aus Lenschitz im selben Jahr 1559 auch Melanchthons Brief aus dem Jahr 1553 über den Streit mit Stancaro druckte („Responsio de controversiis Stancari scripta a Philippo Melanchthone anno domini $\left.1553^{\prime \prime}\right)^{80}$ - was vermutlich in Zusammenhang mit dem Druck von Stancaros „Collatio doctrinae“ geschah.

Der Druck von Stancaros „Collatio doctrinae“ erregte die heftigsten Reaktionen. Alle greifbaren Exemplare des Heftes wurden verbrannt, abgesehen von wenigen Ausnahmen, die man zurückbehielt, um sie als Zeugnis von Stancaros Lehre an einige andere Kollegen schicken zu können (siehe dazu weiter unten in Francesco Lismaninis Brief an Bullinger vom 1. September 1559). Vom 26. bis 28. Juni 1559 hielt man eine Synode in dem ca. 35 Kilometer westlich von Pińczów gelegenen Wodzisław ${ }^{81}$ ab. Auf dieser Synode waren etliche Edelleute

75. Siehe Wotschke, Briefwechsel (wie Anm. 9), 96, Anm. 1; Theodor Wotschke, Francesco Lismanino, in: Zeitschrift der Historischen Gesellschaft für die Provinz Posen, zugleich Zeitschrift der Historischen Gesellschaft für den Netzedistrikt zu Bromberg 18 (1903), 213-332, hier 270, sowie Hein, Italienische Protestanten (wie Anm. 72), 82.

76. Siehe dazu Hein, Italienische Protestanten (wie Anm. 72), 70-73; Urban, „Stancaro“ (wie Anm. 8), 111.

77. Siehe Wotschke, Stancaro (wie Anm. 10), 492f.

78. Dieser hatte im Jahr 1558 seine Druckerei in Pińczów eröffnet; siehe Theodor Wotschke, Herzog Albrechts Briefe an Johann Laski, Teil II (Schluß), in: Altpreußische Monatsschrift 45 (1908), 464 (Anm.).

79. Siehe dazu Wotschke, Stancaro (wie Anm. 10), 493, Anm. 2.

80. Siehe Adam Jocher, Obraz bibliograficzno-historyczny literatury i nauk w Polsce, Wilna 1842, 258, Nr. 3336; Theodorus Wierzbowski, Bibliographia Polonica XV ac XVI ss. Volumen II, Nieuwkoop 1961, 110, Nr. 1381; Melanchthon-Bibliographie III 2196f., Nr. 1559.53.

81. In der Literatur ist öfters der Name „Włodzisław“ angegeben. Sucht man aber diesen Ort auf einer Karte, findet man ihn im nordöstlichen Teil Polens, ungefähr zwischen Kolberg und Stettin und circa $600 \mathrm{~km}$ von Kleinpolen entfernt - die Synode kann dort nicht getagt haben! 
und zahlreiche Pfarrer anwesend, unter ihnen auch der Superintendent Felix Cruciger $^{82}$ sowie der kranke Johannes a Lasco, der ungefähr ein halbes Jahr später verstarb. ${ }^{83} \mathrm{Am}$ 28. Juni stand eine Verwarnung des Druckers Daniel aus Lenschitz auf der Tagesordnung, die auch in den Protokollen vermerkt wurde: „Erstens wurde der Drucker Daniel von den älteren Kirchendienern wegen seiner Untreue zurechtgewiesen; er hat nämlich mehrere unwürdige [Schriften] ohne Erlaubnis und ohne Genehmigung der kirchlichen Zensur gedruckt. Er gelobte Besserung und versprach, künftig nichts mehr ohne Entscheid der Kirche des Herrn Christus zu drucken. Derselbe Daniel hat in Bezug auf die Herausgabe des Büchleins von Stancaro gegen Philipp Melanchthon den Gregor Orsatius beschuldigt: Dieser hätte ihm mit dem Herrn [gemeint ist vermutlich der Herr von Pińczów, Nikolaus Olesnicki $\left.{ }^{84}\right]$ gedroht und ihn zu dem Druck gezwungen." ${ }^{\text {85 }}$

Stancaro geriet darüber sehr in Zorn und schimpfte heftig über Johannes a Lasco, Francesco Lismanini und Felix Cruciger, die sich aber nicht davon abhalten ließen, für den 7. August 1559 eine Synode nach Pińczów einzuberufen. ${ }^{86}$ Dem überlieferten Protokoll dieser Synode (unter deren Teilnehmern an vorrangiger Stelle a Lasco, Lismanini, Stancaro und Cruciger genannt werden ${ }^{87}$ ) ist zu entneh-

Deshalb kann hier nur der Ort Wodzisław (im heutigen Kreis Jędrzejowski) in der Woiwodschaft Heiligkreuz (Świętokrzyskie) gemeint sein.

82. Felix Cruciger war der Superintendent der kleinpolnischen evangelischen Kirche; siehe Wotschke, Lismanino (wie Anm. 75), 244.

83. Siehe Akta Synodów Różnowierczych $\mathrm{w}$ Polsce $=$ Acta synodalia ecclesiarum Poloniae reformatorum, Bd. 1, 1550-1559, hg. v. Maria Sipaytto, Warschau 1966, 304; Menno Smid, Reisen und Aufenthaltsorte a Lascos, in: Christoph Strohm, Hg., Johannes a Lasco (1499-1560). Polnischer Baron, Humanist und europäischer Reformator, Tübingen 2000, 198.

84. Siehe Akta Synodów Różnowierczych w Polsce (wie Anm. 83), 309, Anm. 3.

85. Übersetzung von der Verfasserin des vorliegenden Beitrags. - Im Original: „Die [28e Iunii]. Primo loco, Daniel typographus admonitus est per seniores ministros infidelitatis suae; plura enim et alia quaedam indigna impressit absque consensu et censura ecclesiae. Hic vero emendationem promisit atque sine iudicio ecclesiae Christi Domini sub incudem nihil penitus dabit. Daniel idem de edito libello Stancari contra Philippum Melanchtonem accusavit Gregorium Orsacium, qui minis domini eum coegit ad imprimendum“ (Akta Synodów Różnowierczych w Polsce, wie Anm. 83, 308f.).

86. Siehe Wotschke, Stancaro (wie Anm. 10), 493f. mit Anm. 1. - Bei den Literaturrecherchen fand ich auch einen Eintrag in der „Deutschen Digitalen Bibliothek“, der in diesem Zusammenhang von Interesse sein dürfte: Im Landesarchiv Baden-Württemberg, Abteilung Hauptstaatsarchiv Stuttgart, gibt es im Bestand A 63 (Religions- und Kirchensachen) folgenden Eintrag: „Schriften, betreffend des Stancarus Christologie und deren Verwerfung durch die Synode von Pinczow", https://www.deutsche-digitale-bibliothek.de (letztes Abrufdatum: 04.05.2018). Ich habe diese Akten nicht eingesehen.

87. Siehe Akta Synodów Różnowierczych w Polsce (wie Anm. 83), 310. - Wotschke, Stancaro (wie Anm. 10), 494, Anm. 2, nimmt mit Berufung auf Dalton, Lasciana, 483, Anm.1, an, dass das 
men, was man zuerst thematisierte: nämlich „die häretische Lehre, die Stancaro über Jesus Christus als Mittler verbreitet und in der er mit Nestorius leugnet, dass der eingeborene Sohn Gottes Mittler in der göttlichen Natur sei, sondern allein in der menschlichen Natur, gegen die Wahrheit aller kanonischen Schriften. “88 Über den Verlauf der Synode hat auch Theodor Wotschke in seinem Aufsatz über Stancaro Auskunft gegeben. Zunächst wurde eine Disputation mit Stancaro aus mehreren Gründen abgelehnt: Es war gesetzlich verboten, eine Disputation ohne Erlaubnis des Königs zu veranstalten. Zudem hatte Melanchthon die Lehre Stancaros vorher schon verurteilt, und ohne vorher bekanntgegebene schriftliche Grundlage würde die Disputation ergebnislos sein. Aber „durch sein herausforderndes, großsprecherisches Wesen wußte Stancaro am folgenden Tage (8. August 1559) die Synode doch noch zu einer Disputation zu zwingen. " ${ }^{\text {(89 Damit }}$ hatte er jedoch keinen Erfolg. Ganz im Gegenteil: Wie Wotschke weiter ausführt, beschlossen die Versammelten, ihren Umgang mit Stancaro abzubrechen, seine Schrift öffentlich zu verbrennen, allen Geistlichen und Lehrern ein Glaubensbekenntnis abzuverlangen, etwaige Anhänger Stancaros ihrer Ämter zu entheben und an die Kirchen in Großpolen und Reußen (Ruthenien), in Masowien und Litauen sowie an die Wittenberger und Schweizer zu schreiben, sie über Stancaro in Kenntnis zu setzen und ihre Hilfe zu erbitten. Zudem setzten die Geistlichen bei dem Grundherrn Oleśnicki durch, Stancaro den Aufenthalt in Pińczów zu verbieten.

Aus diesen Beschlüssen folgte, dass Petrus Statorius d.Ä. (Piotr Stoiński, Pierre de Tonneville, gest. 1568/70), der zeitweilige Rektor des Gymnasiums in Pińczów, ${ }^{90}$ einen Bericht über den Streit mit Stancaro verfasste und an Johannes Calvin schickte, ${ }^{91}$ während sich Francesco Lismanini mit einem heute nicht mehr erhaltenen Brief an Melanchthon und Georg Maior nach Wittenberg wandte, ${ }^{92}$ mit einem anderen Schreiben aber an die Zürcher Geistlichkeit.

$\overline{\text { Protokoll der Synode bis auf ein kleines Bruchstück verloren gegangen sei; dabei schrieb Dalton }}$ jedoch lediglich, dass das Protokoll die Verhandlung nur unvollständig wiedergegeben zu haben scheint - was meines Erachtens nicht dasselbe ist.

88. Siehe Akta Synodów Różnowierczych w Polsce (wie Anm. 83), 311.

89. Wotschke, Stancaro (wie Anm. 10), 494-496.

90. Siehe Kęstutis Daugirdas, Die Anfänge des Sozinianismus. Genese und Eindringen des historisch-ethischen Religionsmodells in den universitären Diskurs der Evangelischen in Europa, Göttingen 2016, 178.

91. Statorius' Brief an Calvin datiert vom 20. August 1559 und ist gedruckt in CO XVII, Sp. 600-603, Nr. 3098.

92. Dies teilt Wotschke, Lismanino (wie Anm. 75), 272, mit; siehe auch Wotschke, Briefwechsel (wie Anm. 9), 95, Anm. 1. - Stancaro gelangte an eine Abschrift des Briefes an Melanchthon. 
Dieses Schreiben Lismaninis an Bullinger und an dessen Zürcher Amtskollegen ist erhalten geblieben. Es datiert vom 1. September 1559. ${ }^{93}$ Einen Absendeort hat Lismanini nicht angegeben, aber zweifellos wurde es in Pińczów geschrieben, wo Lismanini seit dem Sommer 1559 lebte. ${ }^{94}$ In diesem Brief deutet Lismanini zunächst die Schwierigkeiten an, die der gerade erst zart keimenden evangelischen Kirche in Polen mit der Bedrohung durch die „pseudoprophetae ${ }^{\text {(995 }}$ entstehen, um dann Folgendes mitzuteilen: „[...] Aber vor allem mögt Ihr mit uns dem ewigen Vater durch Christus danken, dass er sich dazu herabgelassen hat, die Unseren vor dem unheilbringenden Dogma des Stancaro zu bewahren. Kaum war Stancarus hierher zurückgekehrt, hat er die verwerfliche, ketzerische Lehre des Nestorius wieder ins Leben gerufen, was er früher auch schon in der Mark ${ }^{96}$, in Preußen und vor kurzem in Transsylvanien [Siebenbürgen] versucht hat, indem er den Leib Christi von dem Wort in solch einer Weise abgetrennt hat, dass der Leib lediglich bei unserer Versöhnung mit dem Vater eine Rolle spielt, wodurch er uns den bloßen Menschen [Christus] als Mittler hinstellt und alle der arianischen Gottlosigkeit beschuldigt, uns, die nicht auf seine Worte schwören wollten, während er selbst sich keiner Gruppierung ${ }^{97}$ zurechnen will. Er zeigte sich dermaßen gottlos, dass man die versammelte Synode auflösen musste, damit sich nicht irgendein Zweifel in der Gesinnung der Brüder festsetzen würde. Damit Ihr aber begreift, wie sein Urteil über alle christlichen Kirchen beschaffen ist, erhaltet Ihr hier dieses von ihm verfasste und inmitten von uns heimlich gedruckte, berüchtigte Pamphlet. Als er dieses öffentlich verbreitete, wurden die Exemplare zum Teil verbrannt, ${ }^{98}$ zum Teil aber aufbewahrt, um sie an Euch alle senden zu können. Aber auch wenn es den Anschein haben mag, dass diesem Übel genug

Lismanini hatte darin mit seiner Abscheu gegen ihn nicht hinter dem Berg gehalten, und von da an war er Stancaro abgrundtief verhasst; siehe Wotschke, Lismanino (wie Anm. 75), $272 \mathrm{f}$.

93. Druck in: Wotschke, Briefwechsel (wie Anm. 9), 95-97. Der Brief wurde durch Sebastian Pech überbracht; siehe Wotschke, Briefwechsel (wie Anm. 9), 97, Anm. 1, und Wotschke, Lismanino (wie Anm. 75), 272.

94. Seine Wohnung befand sich im Erdgeschoss des Klosters; siehe Wotschke, Lismanino (wie Anm. 75), 269.

95. Vgl. Wotschke, Briefwechsel (wie Anm. 9), 95f., Nr. 174.

96. Gemeint ist damit die östlich der Oder gelegene Landschaft Neumark. Stancaro war im Oktober 1551 dorthin gereist, um sich den Markgrafen Johann (Hans) von Küstrin geneigt zu machen; siehe Hein, Italienische Protestanten (wie Anm. 72), 78.

97. Gemeint ist damit „Partei“ im Sinne von „Faktion“, hier: „Glaubensrichtung“.

98. Wotschke, Briefwechsel (wie Anm. 9), 96, Anm. 2, verweist hierzu auf Hosius, Opera II, 694, der ebenfalls berichtet, dass Stancaros Schrift in Pińczów öffentlich verbrannt worden ist: „Itaque condemnastis eum inauditum, libros eius Vulcano corrigendos tradidistis." In der Marginalie dazu heißt es: „Stancari libri exusti Pinzoviae“ (D. Stanislai Hosii [...] Opera omnia in duos divisa tomos [...], Köln 1584, 694). 
entgegengesetzt worden ist, so haftet trotzdem das Virus dieses so gottlosen Dogmas bis jetzt einigen [Leuten] in ihrem tiefsten Inneren an, und zwar auf eine solche Weise, dass die Kirche keinen unblutigen Sieg davongetragen hat. Daher werdet Ihr dieser Kirche, aber auch der ganzen Welt eine nützliche und angebrachte Hilfe leisten, wenn Ihr durch die Herausgabe des Büchleins diese Angelegenheit von [Jesus Christus als] Mittler ausführlich erklären würdet. Da Ihr uns aber wegen der räumlichen Entfernung nicht durch Eure Anwesenheit behilflich sein könnt, so steht uns unterdessen mit Eurem Gebet und Eurem Rat bei, worum ich Euch schon gebeten habe, was für uns von großer Wichtigkeit ist und worauf wir vertrauen. Der Herr leite Euch mit seinem Geist und möge Euch zum Ruhme seines Namens lange unversehrt erhalten [...]." "999

Daraus geht (wie schon weiter oben erwähnt) hervor, dass nicht alle Exemplare von Stancaros Schrift gegen Melanchthon verbrannt wurden, sondern die Geistlichen einige davon aufhoben, um sie an ihre entfernteren Kollegen senden zu können. Der Brief Lismaninis wurde offenbar von Sebastian Pech, dem Famulus von Johannes a Lasco, ${ }^{100}$ nach Zürich gebracht, denn am 30. Oktober 1559 schreibt Bullinger an Johannes Calvin: Exponet tibi res Polonicas D. Sebastianus noster. ${ }^{101}$ Zweifellos brachte dieser zusammen mit dem Brief auch das von Lismanini erwähnte Exemplar von Stancaros Schrift mit.

Stancaro war nach seiner Ausweisung aus Pińczów mit seiner Familie in das etwa zweihundert Kilometer entfernte Dubiecko in Reußen (Ruthenien), etwa 35 $\mathrm{km}$ westlich von Przemyśl, gezogen. Von dort sandte er über ein Jahr später, am 4. Dezember 1560, ein Schreiben an Wolfgang Musculus, Peter Martyr Vermigli, Johannes Calvin und Heinrich Bullinger, ${ }^{102}$ das er zusammen mit einem ganzen Bündel Bücher nach Genf befördern ließ. In dem Brief stellte er seine Lehre dar und bat darum, sie zu akzeptieren. Unter den mitgesandten Büchern befand sich gewiss auch seine "Collatio doctrinae“, wie aus einer Andeutung Stancaros in

99. Übersetzung von der Verfasserin des vorliegenden Beitrags. Druck des Originals (im lateinischen Wortlaut) in: Wotschke, Briefwechsel (wie Anm. 9), 95-97; der vorliegende Textauszug auf S. 96.

100. Siehe Jan Pierożyński, Z dziejów obiegu informacji w Europie XVI wieku: nowiny z Polski w kolekcji Jana Jakuba Wicka w Zurychu z lat 1560-1587, Krakau 1995, 215.

101. Siehe CO XVII, Sp. 665, Nr. 3127, und Wotschke, Briefwechsel (wie Anm. 9), 97, Anm. 1. - Am 7. Dezember 1559 verfasste übrigens Sebastian Pech einen Bericht über den Streit mit Stancaro und schickte ihn an den flämischen Theologen Jan van Utenhove; siehe Wotschke, Briefwechsel (wie Anm. 9), 98, Nr. 178a.

102. Gedruckt in CO XVIII, Sp. 260-263, Nr. 3288; erwähnt bei Wotschke, Briefwechsel (wie Anm. 9), 120, Nr. 208. 
dem eben genannten Brief ${ }^{103}$ und ferner aus der Anmerkung zu einem Brief von Theodor Beza an Rudolf Gwalther vom 27. Februar [1561] geschlossen werden kann. ${ }^{104}$ Wenn das tatsächlich der Fall war, dürften also - mindestens - zwei Exemplare in die Eidgenossenschaft gelangt sein: das oben schon erwähnte, von Sebastian Pech nach Zürich transportierte Exemplar sowie das von Stancaro selbst nach Genf überschickte Heft. Insbesondere schickte Stancaro aber auch seine Schrift „Examinatio Pinczovianorum super confessionem fidei eorum per Franciscum Stancarum Mantuanum, qua modis omnibus ipsi convincuntur haereseon“ mit. Letztere hatte er gleich nach der Synode vom 7. August 1559 an einem unbekannten Ort publiziert; ${ }^{105}$ Exemplare davon scheinen nicht erhalten zu sein. Gegen Ende 1559 war zudem eine kleine Abhandlung mit dem Titel „De officiis mediatoris domini nostri Jesu Christi et secundum quam naturam haec officia exhibuerit et executus fuerit" aus seiner Feder geflossen. ${ }^{106}$ Es würde jedoch das Anliegen und das Ziel dieser kurzen Studie - nämlich die Wiedergabe des Wortlauts der "Collatio doctrinae“ - weit überschreiten, wenn ich nun auch die einige Zeit später erfolgte Reaktion der Zürcher und den weiteren Gang der Ereignisse darstellen würde. Verwiesen sei dafür auf die Briefsammlung von Theodor Wotschke, auf dessen Studie über Stancaro sowie auf den Kommentar in Band 3 der eben erwähnten Korrespondenz Theodor Bezas.

\section{ERWÄHNUNGEN VON STANCAROS SCHRIFT IN DER SEKUNDÄRLITERATUR}

Der Königsberger Gelehrte Friedrich Samuel Bock gab im Jahr 1779 den ersten Band seiner Geschichte der Antitrinitarier heraus, in dem er Stancaro und seine Schrift „Collatio doctrinae“ in einem Kapitel über Giorgio Biandrata erwähnt. ${ }^{107}$ Bock verweist darin auf ein eigenes Kapitel über Stancaro, in dem die Schrift unter „Nr. 20“ angeführt sei; doch hat er einen solchen eigenen

103. Stancaro schrieb: „ut in historia quam ad vos mittimus, et clarius et distinctius videbitis“ (CO XVIII, Sp. 261).

104. Siehe Correspondance de Théodore de Bèze, recueillie par Hippolyte Aubert, hg. v. Henry Meylan, Alain Dufour, Bd. III (1559-1561), Genf 1963, 86f., Anm. 2.

105. Siehe ebd., 87, Anm. 2.

106. Siehe Hein, Italienische Protestanten (wie Anm. 72), 107f. - Zwei Abschriften dieser Schrift liegen im Stuttgarter Hauptstaatsarchiv; siehe Paul Oskar Kristeller, Iter Italicum. Accedunt alia itinera, Bd. 3 (Alia Itinera I), London, Leiden 1983, 696; siehe auch oben Anm. 86.

107. Friedrich Samuel Bock, Historia Antitrinitariorum, 2 Bde., Königsberg, Leipzig 17791784, Bd. 1/1, 57. Vgl. auch Wotschke, „Stancaro“ (wie Anm. 10), 493, Anm. 1. 
Abschnitt über Stancaro dann offenbar nicht mehr geschrieben. Jedenfalls ist er im zweiten Teil des ersten Buches seiner Geschichte der Antitrinitarier nicht zu finden. Vermutlich wird Bock im Laufe der Zeit klar geworden sein, dass es sich bei Stancaro nicht um einen Antitrinitarier, sondern um einen Nestorianer gehandelt hat. ${ }^{108}$

Die Zeugnisse, die der Historiker und Theologe Theodor Wotschke in seinen Werken über Stancaros Schrift „Collatio doctrinae“ zusammengetragen hat, sind in das vorige Kapitel des vorliegenden Aufsatzes eingeflossen.

Auch der Historiker und Politiker Francesco Ruffini hat in seinen „Studi sui riformatori italiani“ die Schrift erwähnt, wobei er sich auf Wotschke stützte. ${ }^{109}$

In der Melanchthon-Bibliographie des Germanisten Wilhelm Hammer ist die Schrift „Collatio doctrinae“ im ersten Band unter Angabe des Druckers und des Jahres verzeichnet: „Daniel Lancisius (aus Łęczyca [Lentschitza, Bez. Łódź]), 1558/59." Ein Exemplar der Schrift war damals allerdings nicht bekannt, was von Hammer ausdrücklich vermerkt wurde. ${ }^{110}$

Der Theologe Lorenz Hein hat im Jahr 1967 in einem Aufsatz über Stancaro in Polen angegeben, dass ein Exemplar der Schrift "Collatio doctrinae“ im Staatsarchiv Zürich unter der Signatur E II 371 vorhanden sei. ${ }^{111}$ In einer umfangreicheren Studie aus dem Jahr 1974 über italienische Protestanten und ihren Einfluss auf die Reformation in Polen hat er diese Angabe wiederholt und die Schrift dabei benutzt. ${ }^{112}$

Der Historiker Wacław Urban hat in einem Aufsatz über Stancaro die Schrift ebenfalls erwähnt und mitgeteilt, dass ein Exemplar davon in der Zentralbibliothek Zürich [sic] erhalten geblieben sei. ${ }^{113}$

108. Darauf weist Bock, Historia Antitrinitariorum (wie Anm. 107), Bd. 2, $549 f$., hin.

109. Ruffini, Studi (wie Anm. 20), $210 f$.

110. Wilhelm Hammer, Die Melanchthonforschung im Wandel der Jahrhunderte. Ein beschreibendes Verzeichnis, Bd. 1: 1519-1799, Gütersloh 1967, 153, Nr. 194.

111. Lorenz Hein, Francesco Stancaro. Sein Auftritt in Polen und die Antastung der altkirchlichen Lehrgrundlagen, in: Kyrios. Vierteljahresschrift für Kirchen- und Geistesgeschichte Osteuropas 7 (1967), 137-178, hier 161, Anm. 118.

112. Hein, Italienische Protestanten (wie Anm. 72), 97, Anm. 118.

113. Wactaw Urban, Die großen Jahre der stancarianischen „Häresie“ (1559-1563), in: Archiv für Reformationsgeschichte 81 (1990), 309-319, hier 311. - Mit dem in der Zentralbibliothek Zürich befindlichen Exemplar dürfte dasjenige gemeint sein, das heute im Staatsarchiv Zürich aufbewahrt wird. Es ist im Zürcher Onlinekatalog verzeichnet, in dem u. a. (aber nicht ausschließlich) die Bestände der Zentralbibliothek aufgenommen sind. 


\section{VORBEMERKUNGEN ZUM TEXT UND ZUR EDITION}

1. Generelle Bemerkungen zum Text. Stancaro druckte in seiner Argumentation zunächst einige Stellen ab, die er dem "Sermo Arrianorum“ entnommen hatte. Das ist eine anonym verfasste Schrift aus der Spätantike, die dem sogenannten lateinischen Späthomöertum zuzuordnen ist. ${ }^{114} \mathrm{Zu}$ ihrer eigentlichen Entstehungszeit wurde bisher in der Literatur jedoch nichts Genaueres festgestellt. Mit dem Begriff „Homöer“ (oder „Homöousianer") werden die Vertreter einer Wesensähnlichkeit zwischen Vater und Sohn bezeichnet, die sich damit von den sogenannten Anhomöern (das heißt den radikalen Arianern) und den Nizänern (die die Wesensgleichheit von Vater und Sohn betonten) unterschieden. ${ }^{115}$

Der „Sermo Arrianorum“ wurde von einem Gemeindemitglied oder Kleriker namens Dionysius aus dem Vicus Iuliani, etwa 25 Meilen von Hippo Regius entfernt, an Augustin, den Bischof von Hippo (geb. 354, gest. 430), übermittelt. Dieser stellte die Schrift seiner im Herbst des Jahres 419 verfassten Widerlegung „Contra sermonem Arrianorum“ unmittelbar voran. ${ }^{116}$ Um nun aber von seiner Widerlegung auf die entsprechenden Bezugsstellen im „Sermo Arrianorum "verweisen zu können, benutzte Augustin ein numerisches Referenzsystem, ${ }^{117}$ mit dem er dem Leser eine Hilfestellung beim Hin- und Herspringen zwischen beiden Texten gab und welches er in einem Prolog zu seiner eben genannten Widerlegung dargelegt hat. Dieser Prolog wurde (abgesehen von älteren Textausgaben) bisher, soweit ich sehe, nur von Pierre-Marie Hombert in seine Edition mit übernommen. ${ }^{18}$ Stancaro hat dieses Referenzsystem in seiner Schrift ebenfalls angewendet (siehe dazu unten unter Punkt V.2.).

114. Siehe Augustinus, Sermo Arrianorum. Contra sermonem Arrianorum. Collatio cum Maximino Arrianorum episcopo. Contra Maximinum Arrianum. Antiarianische Schriften. Zweisprachige Ausgabe, eingeleitet, übersetzt und hg. v. Hermann-Josef Sieben, Paderborn, München, Wien, Zürich 2008 (Augustinus Opera. Werke, Bd. 48), 21. - Weitere moderne Editionen des Textes wurden im Jahr 2000 durch Max Josef Suda (Corpus Scriptorum Ecclesiasticorum Latinorum, Bd. 102) und im Jahr 2009 durch Pierre-Marie Hombert (Corpus Christianorum, Series Latina, Bd. 87 A; siehe dazu unten Anm. 118) herausgebracht.

115. Siehe Gisbert Greshake, „Homöer“, in: Lexikon für Theologie und Kirche, Bd. 5, 3. Aufl. Freiburg, Basel, Rom, Wien 1996, Sp. 251.

116. Siehe Augustinus, Sermo Arrianorum (wie Anm. 114), 18-25.

117. Siehe dazu ausführlich Clemens Weidmann, Prolog und Verweissystem in Contra sermonem Arrianorum. Edition eines nicht erkannten Augustinustexts, in: Wiener Studien 119 (2006), 173-197.

118. Sancti Aurelii Augustini Contra Arrianos opera. Sermo Arrianorum anonymus. Contra sermonem Arrianorum. Conlatio cum Maximino. Contra Maximinum libri duo, cura et studio Pierre-Marie Hombert, Turnhout 2009 (Corpus Christianorum, Series Latina, Bd. 87 A), 159. 
In welcher Edition fand nun Stancaro den „Sermo Arrianorum“? Wie er am Anfang seiner Streitschrift selbst angibt, lag ihm dieser Text in Band 6, Spalte 652ff. der Gesamtausgabe von Augustins Werken vor: „Arrii et Arrianorum sententiae de filio dei secundum divinitatem in sermone Arrianorum descriptę tomo 6 operum divi Augustini, columna 652 et ultra. ${ }^{\text {" } 119}$ Gemeint ist damit nicht die ältere Edition von Konrad Leontorius, Johannes Amerbach u.a. (Basel 1506), sondern die neuere, von Erasmus von Rotterdam besorgte und von Hieronymus Froben in Basel verlegte Ausgabe, die zuerst in den Jahren 1527 bis 1529 erschienen war ${ }^{120}$ und mehrere Auflagen in unterschiedlicher Gestalt erlebte. Ein Vergleich ergibt, dass Stancaro den Band 6 der Ausgabe Basel 1542 (VD 16 A 4149) ${ }^{121}$ oder Basel 1556 (VD 16 ZV 22414) benutzt haben muss. In diesen beiden Auflagen ist die Einteilung in Kolumnen zu finden, und dort ist in Band 6 von Sp. 652 bis 656 der „Sermo Arrianorum“ abgedruckt.

Stancaro gliederte seine Darstellung in die folgenden vier Abschnitte:

[1.] von f. A1v. bis A4r.: „Propositio“: eine synoptische Gegenüberstellung von Thesen aus dem „Sermo Arrianorum“ sowie aus Werken von Melanchthon und seiner Anhänger („sequaces“, wie er sie auf dem Titelblatt f. A1r. nannte).

[2.] von f. A4r. bis A6r.: „Arrii et Philippi Melanchthonis et Francisci Davidis et reliquorum Saxonum doctrina de filio dei, domino nostro Iesu Christo, una est et eadem": eine synoptische Gegenüberstellung von verworfenen arianischen Auffassungen aus den Kirchenvätern und zeitgenössischen Autoren sowie Stellen aus Werken Philipp Melanchthons.

[3.] von f. A6r. bis A7v.: „Philippus Melanchthon et Franciscus Davidis cum complicibus Arrianae haereseos convincuntur, ex ore proprio“: ein Resümee aus den vorangegangenen Vergleichen.

[4.] von f. A7v. bis A10v.: „Arrii doctrina de filio dei, succincte perstringitur": eine Darstellung der arianischen Lehre vom Gottessohn.

2. Das Verweissystem. Zur Kenntlichmachung der Bezugsstellen wandte Stancaro dasjenige Referenzsystem mit Ziffern an, das - wie oben unter V.1. beschrieben - von Augustin angelegt worden war. Die Ziffern übernahm Stancaro von

119. Francesco Stancaro, Collatio doctrinae [...], f. Alv.

120. Siehe Alexandre Vanautgaerden, Érasme typographe. Humanisme et imprimerie au début du XVI ${ }^{\mathrm{e}}$ siècle, Genf 2012, 519.

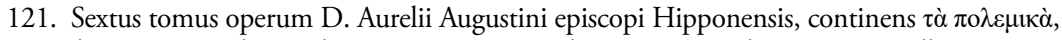
hoc est, decertationes adversus haereses, praecipue Iudaeorum, Manichaeorum, Priscillianistarum, Origenistarum, Arrianorum et Ioviniani, Basel: Froben, 1542. 
den Marginalien im Druck des "Sermo Arrianorum“ aus der eben erwähnten Ausgabe Basel 1542 oder 1556. In die heutigen, modernen Textausgaben des „Sermo Arrianorum“ sind die Ziffern auch aufgenommen worden (allerdings stehen sie dort nicht mehr am Rand, sondern - viel übersichtlicher - direkt vor den entsprechenden Textstellen). Man kann also heutzutage die von Stancaro bezeichneten Textstellen im „Sermo Arrianorum“ auch dann auffinden, wenn man die Basler Augustin-Ausgabe nicht zur Hand hat.

3. Beschreibung der Textvorlage. Die Textvorlage für die Edition ist das einzig bekannte Exemplar des Druckes. Es wird im Staatsarchiv Zürich (Zürich StA) unter der Signatur E II 371, f. 748r.-757v., aufbewahrt.

Das Exemplar ist eingebunden in den Band E II 371 (im Onlinekatalog des Staatsarchivs wird er mit der Signatur E II 371a bezeichnet). Dieser Band gehört zum Bestand „Antistitialarchiv“ und enthält Briefe mehrerer Reformatoren (neben Bullinger z.B. Johannes Calvin, Theodor Beza, Simon Sulzer) aus den Jahren 1550-1572.

Das Exemplar wurde handschriftlich foliiert. Die Foliierung reicht von 748r. bis 757v. Sie stammt von zwei verschiedenen Händen, wobei die ältere Hand jeweils nur die Rectoseiten foliiert hat, die jüngere Hand hingegen die Versoseiten. (Die Foliierung wurde nicht mit in die Edition übernommen!)

Der Druck ist im Oktavformat $\left(8^{\circ}\right)$ gehalten und besteht aus einer Lage von zehn Blättern, die von $\mathrm{f}$. A1r. bis f. A10v. reicht $\left(\mathrm{A}^{10}\right)$. Die Lagen sind lediglich auf den Seiten A2r., A3r. A4r. und A5r. angegeben. Die Schrift ist weder foliiert noch paginiert.

Die Seiten sind mit Kustoden und lebenden Kolumnentiteln versehen. Die lebenden Kolumnentitel beginnen auf f. A1v. (wobei je zwei Titel mit Ausnahme des letzten eine Einheit bilden) und lauten wie folgt:

A1v., A2v., A3v., A4v., A5v.: Collatio doctrinae Arrii. ${ }^{122}$

A2r., A3r., A4r., A5r., A6r.: $\quad$ Et Melanchthonis. ${ }^{123}$

A6v.:

Philippus cum suis

A7r.:

haereseos convincuntur.

122. Auf f. A3v. und A4v. abweichend: Collatio doctrinae Arii.

123. Auf f. A3r. verdruckt: Et Melachthonis; auff. A4r. abweichend: Et Philippi Melan.; auff. A5r. und A6r. abweichend: Et Melanthonis. 
A7v., A8v., A9v.: Doctrina Arrii ${ }^{124}$

A8r., A9r., A10r.: de filio dei.

A10v.: Doctrina Arrii de filio dei.

Auf dem Titelblatt finden sich ein Ober- und ein Untertitel (siehe unten). Oberhalb des Titels steht ein handschriftlicher Vermerk: „Libellus famosus furiarum Francisci Stancari“. Wie ein Handschriftenvergleich mit dem Brief Francesco Lismaninis an Heinrich Bullinger vom 1. September 1559 zeigt, wurde dieser Vermerk von Lismanini selbst angebracht. Das Exemplar, welches Theodor Wotschke seinerzeit vorlag, falls es sich tatsächlich um ein anderes als das in Zürich aufbewahrte Exemplar handelte, trug einen fast gleichlautenden handschriftlichen Vermerk. ${ }^{125}$ Unter dem Titel findet sich eine gedruckte Titelvignette in Gestalt eines kunstvollen, mehrfach verschlungenen Bändchens. Auf f. A6r. findet sich links neben der Überschrift ein florales Zierelement.

4. Zur Textgestalt der vorliegenden Edition. In der vorliegenden Edition wurde die Lagenzählung der Vorlage (f. A1r. bis A10v.) verzeichnet. Wo sie in der Vorlage sichtbar ist, wurde sie hier in spitzen Klammern wiedergegeben; wo sie in der Vorlage nicht sichtbar ist, wurde sie hier in eckige Klammern gesetzt. Auf die Übernahme der (handschriftlichen) Foliierung wurde, wie oben schon bemerkt, verzichtet.

Die Seitenumbrüche der Vorlage sind in der vorliegenden Edition in Form von || gekennzeichnet. Die Kustoden ${ }^{126}$ aus der Vorlage wurden nicht mit übernommen. Die Marginalien wurden in spitze Klammern gesetzt. Die Marginalien auf f. A8r., A8v., A9v., A10r. und A10v. sind vom Drucker in gotischen Lettern (Textura) gesetzt worden; dies wurde in der vorliegenden Edition nicht besonders gekennzeichnet.

Verzierte Initialen in der Vorlage („A“ auf f. A1v.; „P“ auf f. A2r.) wurden als Versalien wiedergegeben. Versalien im Titel, in den Kolumnentiteln und im Text wurden als solche beibehalten.

Die Orthographie und die Interpunktion wurden behutsam normalisiert, das heißt an heutige Gepflogenheiten im Umgang mit lateinischen Texten an-

124. Auf f. A8v. und A9v. abweichend: Doctrina Arii.

125. Siehe dazu Hammer, Melanchthonforschung (wie Anm. 110).

126. Kustoden stehen ganz am Seitenende und bestehen aus dem Wort, mit dem die jeweils nächste Seite beginnt (manchmal ist statt eines ganzen Wortes auch nur eine Silbe angegeben). Sie dienten als Hilfestellung für den Buchbinder. 
gepasst. Dies hat auch zur Folge, dass die in der Vorlage überreichlich verwendeten Kommata reduziert wurden. Gleiches gilt für die Groß- und Kleinschreibung: Auch sie wurde normalisiert. Die Buchstabenverbindung „ij“ ist als „ii“ wiedergegeben worden. Abkürzungen wurden stillschweigend aufgelöst (zum Beispiel wurde das Zeichen „\&“ aus der Vorlage als „et“ wiedergegeben; „doct.“ in der Vorlage entspricht „doctrina“ in dem vorliegenden Text; „,col.“ = „columna“, usw.). Ausnahme: Die Abkürzung „etc.“ wurde unverändert beibehalten.

Zur Absatzeinteilung in der Vorlage ist Folgendes zu bemerken. Die ersten zehn Seiten der Vorlage sind synoptisch angelegt, das heißt links (auf den Versoseiten) finden sich die Thesen der Arianer, und rechts (auf den Rectoseiten) diejenigen Melanchthons. Der Drucker hat diese Anordnung auch mithilfe der lebenden Kolumnentitel sichtbar gemacht: links oben erscheint jeweils der Name von Arius, rechts oben der von Melanchthon. Zudem sind den einzelnen Textabschnitten am Rande Ziffern beigegeben, die die jeweilige Stelle im „Sermo Arrianorum “ (zu der von Stancaro herangezogenen Ausgabe siehe oben unter V.1.) bezeichnen und sich jeweils aufeinander beziehen. Diese synoptische Aufteilung der Seiten konnte allerdings in der Vorlage nicht strikt durchgehalten werden, so dass es zu Textverschiebungen kam. Diese Verschiebungen sind in der vorliegenden Ausgabe durch die Lagenzählung ersichtlich.

Um die synoptische Aufteilung der Seiten in der vorliegenden Ausgabe beibehalten zu können, wurden die gegenüberstehenden Abschnitte direkt untereinander wiedergegeben, und zwar so, dass der Text der Versoseiten in Grundschrift und derjenige der Rectoseiten (außer der Titelseite) in Kursive von mir wiedergegeben wurde.

\section{EDITION}

[Titelblatt: A1r.] Collatio doctrinae Arrii et Phi-||lippi Melanchthonis et sequacium. || ARRII ET || PHILIPPI MELANCHTHONIS || ET FRANCISCI DAVIDIS ET || reliquorum Saxonum doctrina || de filio dei, domino no-||stro Iesu Christo, una \|| est et eadem.

[A1v.] ARRII ET AR $\|$ rianorum sententiae de filio dei secundum divinitatem in sermone Arrianorum descriptę tomo 6 operum divi Augustini, columna 652 et ultra. 
$<\mathrm{A} 2 \mathrm{r}$.> PHILIPPI MELANchthonis, Casparis Helthi ${ }^{127}$, Francisci Davidis ${ }^{128}$ et Matthiae Hebler ${ }^{129}$ Cibiniensis ${ }^{130}$ Plebani ${ }^{131}$ cum similibus doctrina de filio dei secundum divinitatem etc.

\section{[A1v./A2r.] PROPOSITIO.}

[A1v.] 13. Filius et spiritus sanctus mittuntur.

$<\mathrm{A} 2 \mathrm{r} .>13$. Filius et spiritus sanctus mittuntur. In libello de controversiis Stancari edito.

[A1v.] 22. Filius orat et interpellat patrem pro nobis.

$<\mathrm{A} 2 \mathrm{r} .>22$. Filius dei orat, intercedit, postulat, supplicat. In epistola ad electorem Brandeburgensem ${ }^{132}$ et in libro contra Stancarum edito et in scriptis Francisci Davidis et Helti.

[A1v.] 14. Filius est minister patris. Divus Cyrillus tomo 3 ad reg[inas] columna 331.

$<\mathrm{A} 2 \mathrm{r} .>14$. Filius minister est patris, hoc est sacerdos, pontifex et mediator. In libro contra Stancarum edito et in epistola ad praedictum electorem et in libro dictato Torgae.

[A2v.] 15. Filio imperat pater.

$<$ A3r.> 15. Filio imperat pater: Postula a me et dabo tibi gentes haereditatem, Psal. 2. Ad electorem Brandeburgensem et in libro contra Stancarum edito.

[A2v.] 16. Filius subditus est patri.

$<$ A3r.> 16 Filius subditus est patri, subiectus, obediens, exinanitus et humiliatus. In praedictis scriptis et in suis locis communibus, pagina 40.

127. Kaspar Helt (auch: Helth; ungarisch: Gáspár Heltai), ungarischer Bibelübersetzer, Pfarrer in Klausenburg von 1544 bis 1574, ab 1559 helvetisch/reformiert; siehe MBW Bd. 12, Personen F-K (wie Anm. 13), 265 (mit weiterer Literatur); Anita Andrea Széll, Deutsch-ungarische Sprachbeziehungen: Kaspar Helth, Autor und Verleger, Berlin 2016.

128. Franz (Franciscus) Davidis (Ferenc Dávid), unitarischer Theologe; geb. 1510 (älterer Literatur zufolge) oder 1520 (neuerer Literatur zufolge) in Klausenburg (Koloszvár, Cluj), gest. 15. November 1579 in Haft auf der Festung Déva in Siebenbürgen; siehe MBW Bd. 11, Personen A-E, bearbeitet von Heinz Scheible unter Mitwirkung von Corinna Schneider, Stuttgart-Bad Cannstatt 2003, 339f. (mit weiterer Literatur); Mihály Balázs, Ungarländische Antitrinitarier IV. Ferenc Dávid, Baden-Baden, Bouxwiller 2008.

129. Matthias Hebler, Superintendent (Bischof) der Deutschen in Siebenbürgen; gest. 18. September 1571 in Hermannstadt; siehe MBW Bd. 12, Personen F-K (wie Anm. 13), 239f. (mit weiterer Literatur).

130. Cibinium: Hermannstadt (Nagyszeben; Sibiu) in Siebenbürgen.

131. Plebanus: Dorfpfarrer; siehe Adam Friedrich Kirsch, Abundantissimum cornu copiae linguae Latinae et Germanicae selectum, Leipzig 1774, Sp. 2180.

132. Joachim II. von Brandenburg (geb. 1505, gest. 1571), von 1535 bis 1571 Kurfürst von Brandenburg. 
[A2v.] 18. Filius adorat et honorat patrem.

$27 . \quad$ Filio maior est pater.

$<\mathrm{A} 3 \mathrm{r} .>18$ infra [et] 27. Filius dei minor est patre, quia orat, supplicat, sed quia verbo aequalem patri dicunt, re autem non, haec blasphemia Arriana peior est.

[A2v.] 26. Filio pater deus et dominus est.

[A2v.] 33. Filius ut sacerdos adorat deum suum. Filius minister est et summus sacerdos patris sui.

[A3v.] 38. Filius orat et gratias agit, mandatum accipit, supplicat, subditus est et sacerdos est.

[A3v.] 40. Filius humiliatus est et subiectus est et patrem rogat. Haec omnia agit filius dei secundum divinitatem, ait Arrius et sequaces.

$<$ A4r.> 15. 18. 28. 33. 38. 40. Filius dei cum orat et supplicat et mandatum accipit, adorat et honorat patrem ut deum et dominum suum. Minister est et summus sacerdos patris sui. Rogat eum et illi gratias agit. Haec omnia secundum divinitatem filius agit, ait Philippus Melanchthon et sequaces. Cyrillus in Ioannem libro 9 capite 42 columna 471. scribit contrarium, et libro 2 capite 92 columna 106: Adorat ut homo, adoratur ut deus.

\section{<A4r.> ARRII ET PHILIPPI MELANCH-\|THONIS ET FRANCI-\|s-} ci Davidis et reliquorum Saxonum doctrina de filio dei, domino nostro Iesu Christo, una est et eadem.

[A4v.] ARRII ET ARRIANOrum quasdam alias blasphemias, quae non habentur expressae in sermone Arrianorum apud divum Augustinum loco supra citato, sed apud sanctos patres hinc inde sparsas et ab eis confutatas invenimus.

$<$ A5r.> PHILIPPI MELANCHthonis et sequacium quaedam aliae blasphemiae, quae non habentur expressae in loco praefato apud divum Augustinum, sed in scriptis sanctorum patrum inveniuntur allegatae et confutatae.

[A4v.] 1. Filius dei secundum divinitatem gloriam sibi dari ac restitui orat et postulat. Cyrillus in libro Thezauri 10 capite 2 columna 116 et 117 et capite 9 columna 133 tomo 2 et in Ioannem libro 11 capite 17 columna 545 tomo 1 . Sic et alii patres ut divus Augustinus tractatu in Ioannem 105 et Martinus Bucerus in capite 17 Ioannis et Basilius libro 4 contra Eunomium carta 175.

$<\mathrm{A} 5 \mathrm{r}$.> 1. Filius dei secundum divinitatem gloriam sibi dari ac restitui orat et postulat. Philippus Melanchthon in suis locis communibus pagina 43 et in epistola ad electorem Brandeburgensem scripta Ianuarii 12. anno 1553. et in libello contra Stancarum edito. 
[A4v.] 2. Filius dei haereditatem gentium et regnum a patre petit sibi dari Divus Cyrillus in Ioannem libro 11 capite 18 columna 547 tomo 1. Lutterus in Psalmum tomo 2.

$<\mathrm{A} 5 \mathrm{r}$. $>$ 2. Filius dei haereditatem gentium et regnum a deo patre sibi dari petit et orat. Et inde concludit filium dei secundum divinitatem etiam ante incarnationem orasse. Quod argumentum etiam arripuit (ut Lutterus quoque ait in Psalmo 2) Arrius contra divinitatem Christi.

[A5v.] 3. Filius dei intravit in arcanum divinitatis et in ipsum coelum. Cyrillus tomo 3 ad reginas columna 364 .

[A6r.] 3. Filius dei intravit in arcanum consilium divinitatis et in ipsum coelum secundum divinitatem. In epistola ad electorem Brandeburgensem et in libro contra Stancarum edito.

[A5v.] 4. Filius dei placat iram patris, id est portat peccata et punitur, quod Manichaicum est. Cyrillus tomo $4^{133}$ ad reginas columna 366. Vide indicem. Stancari de filio dei et libros eius contra novos Arrianos scriptos.

[A6r.] 4. Filius dei placavit iram patris et cessit irae eius adversus peccata, et natura divina flii obedivit patri in passione, ut in suis locis communibus pagina 40 et in epistola ad electorem scripta Torgae 3. Octobris 1552. Vide librum Stancari.

\section{[A6r.] PHILIP-||PUS MELANCHTHON ET FRANCISCUS DAVI-\|dis cum complicibus Arrianae haereseos convincuntur ex ore proprio.}

[A6v.] EX HAC COLLATIOne diligenter facta manifestum evadit Philippi Melanchthonis, Casparis Helti, Francisci Davidis et Matthiae Hebler, Plebani Cibiniensis, cum complicibus doctrinam de filio dei, domino nostro Iesu Christo, Arrianam esse, et per consequens haereticam, damnatam et reprobatam a tota universali ecclesia authoritate verbi dei a mille et ducentis annis et ultra. Hanc pestiferam haeresim Arrianam in omni aetate, quicunque vere Christiani fuerunt et in hac nostra aetate sunt, damnarunt et reiecerunt ab ecclesia Christi. Vide Lutterum de novissimis verbis Davidis prophetae pagina 109 et 132, et confessionem Augustanam, in qua omnes omnium Germanorum, qui evangelium Christi acceperunt ecclesiae, hanc ter maledictam Arrii haeresim damnant,

133. Richtig ist: 3 . 
repro-||[A7r.]bant. Idem facit et Philippus Melanchthon ${ }^{134}$ in apologia praefatae confessionis in 1 articulum et maxime in capite 14 epistolae ad Romanos pagina 360. Hoc idem facit Franciscus Davidis, qui cum publice et solemniter in Radnoth ${ }^{135}$ 2. Ianuarii 1558 in collatione inter nos facta praesidente magnifico domino Antonio de Kend ${ }^{136}$, coram eo et egregio viro domino Ladislao de Meczke ${ }^{137}$, regni Transylvanię pronotario, et coram multis aliis tam sacerdotibus quam nobilibus et laicis mihi interroganti eum, num Augustanam confessionem acciperet et approbaret, respondisset se accipere et approbare; cunque praedicta confessio manifeste damnet una cum quibusdam aliis haeresibus Arrianam haeresim, quam ipse, Franciscus Davidis, cum suo Philippo Melanchthone et similibus nunc profiteatur et doceat, iure tam $\|[A 7 \mathrm{v}$.] seipsum quam suos Arrianae haereseos condemnavit et condemnat. Quid praeterea disputatione aut testibus opus est? De ore enim suo iudicandus est servus nequam, ${ }^{138}$ sicut Cain, Iudas, Saul et Franciscus Spira ${ }^{139}$ seipsos iudicarunt et condemnarunt.

\section{ARRII DO-||CTRINA DE FILIO || Dei, succincte perstrin-||gitur.}

$<$ Divinitas christi secundum Arrianos. $>$ HOC AUTEM AD REctum iudicium iudicandum necessario requiritur, ut rite cognoscant iudices, quidnam de filio dei Arrius et Arriani sentiebant et isti nunc sentiunt.

Volebant enim Christum secundum divinitatem non esse verum \|[A8r.] $<$ Epiphanius 353 et deinceps et sic omnes sancti patres.> deum neque de substantia dei patris ab aeterno, ante omne tempus, genitum, neque patri per omnia coaequalem et consubstantialem, sed ex nihilo creatum a deo patre, et ideo

134. In der Vorlage: Melanchton.

135. Die siebenbürgische Kleinstadt Iernut (ungarisch: Radnót, deutsch: Radnoten), im Kreis Mureş (Rumänien).

136. Anton Kendi (gest. im Frühjahr 1559), ein ungarischer Magnat, bei dem Stancaro seit 1557 Schutz gefunden hatte und als Militärarzt in Dienst stand; siehe Hein, Italienische Protestanten (wie Anm. 72), 82.

137. Ladislaus Mecskei, fürstlicher Protonotar; siehe Gustav Gündisch, Peter Haller, Bürgermeister von Hermannstadt und Sachsengraf (1550-1569), in: Südostdeutsches Archiv 32/33 (1989/1990), 73.

138. Vgl. Lk 19, 22.

139. Francesco Spiera (geb. 1498, gest. am 27. Dezember 1548) war ein italienischer Jurist, der sich dem evangelischen Glauben zugewandt hatte und sich dafür im Mai und Juni 1548 in einem Prozess vor der Inquisition in Venedig verantworten musste. Er schwor ab, geriet deshalb in stärkste Gewissensqualen, erkrankte psychisch und starb bald darauf. Dass er Selbstmord beging, ist eine spätere Behauptung. Sein Schicksal wurde Thema mehrerer Darstellungen. Siehe Karl Roenneke, Francesco Spiera. Eine Geschichte aus der Zeit der Reformation in Italien, Hamburg 1874; Lucia Felici, „Spiera, Francesco“, in: Dizionario biografico degli Italiani, Bd. 93, Rom 2018, 602-604. 
perfectissimam creaturam vocabant, per quam veluti organum deus cuncta creavit.

$<$ Humanitas Christi secundum eosdem Arrianos. Epiphanius pagina 370. 371. 476. 489. $>$ Hanc filii divinitatem dicebant in tempore assumpsisse carnem humanam, animatam tantum anima sensitiva, non autem anima rationali, hoc est imperfectam humanitatem, id est, humanam carnem veluti pecoris et alicuius animalis irrationalis.

$<$ Divus Augustinus tomo 6 contra Felicianum Arrianum capite 13 columna 786> Hanc itaque Christi humanitatem sine anima rationali et mente, cum viderent Arriani nullam perfecti hominis operationem agere posse (ut orare, supplicare, mediare ${ }^{140}$, sacerdotem et pontificem agere, obedire); cunque viderent Christum dominum orantem, supplicantem, mediantem \|[A8v.] et deo ministrantem, dixerunt Christum non esse verum deum, sed perfectissimam creaturam, quae haec et similia opera faceret.

$<$ Epiphanius pagina 353> Nam, si (ait Arrius) filius dei genitus esset ab aeterno de substantia patris, omnino ei aequalis esset in maiestate, gloria et potestate. Et ideo omnia, quae a patre rogat, concederet et daret, non autem postularet, sed quia postulat et rogat, ideo verus deus non est, neque de substantia patris genitus. Hinc Arrius et sequaces eius sexcentas et amplius blasphemias in filium dei et in spiritum sanctum quoque iaculari conati sunt, ut divus Epiphanius scribit. Nam omnes locos cum veteris tum novi testamenti, qui de Christo domino loquuntur, perperam interpretabantur et corrumpebant, ut nunc faciunt Philippus Melanchthon et Franciscus Davidis cum sequacibus. Quo fit, ut ||[A9r.] totam Christianam religionem ex ecclesia proscribant, et totum Christum, imo totam sanctam trinitatem, conculcent. Verum si Arrius potuisset credere filium Dei perfectam humanitatem, hoc est perfectum hominem, carne humana et anima rationali constantem, assumpsisse, in qua humanitate ea, quae supra dicta sunt, et alia opera humana, quae in sacro leguntur evangelio a domino facta, fecisset, hęc non ad eius divinitatem transtulisset, sed ad eius humanitatem; et divinitatem filii de substantia patris ab aeterno genitam esse credidisset.

Peccavit itaque Arrius contra et divinitatem et humanitatem Christi, dicens eius divinitatem non esse de substantia dei patris, sed creaturam perfectissi-

140. mediare = vermitteln; siehe [Charles du Fresne, sieur] $d u$ Cange, Glossarium mediae et infimae Latinitatis, Bd. 4, unveränderter Nachdruck der Ausgabe von 1883-1887, Graz 1954, 320; Johann Philipp Krebs, Franz Xaver Allgayer, Antibarbarus der lateinischen Sprache, 5. Aufl., Frankfurt a. M. 1876, 692. 
mam, per quam pater omnia creavit, $\mathrm{uti}^{141}$ per organum et instrumentum aliquod, humanitatem vero ${ }^{142}$ eius non esse perfectam, sed im- $\|[A 9 v$.$] perfectam,$ id est carnem quidem humanam, sed sine anima rationali et mente. Hinc est, quod omnia opera, quę Christus faciebat secundum suam veram et perfectam humanitatem, ad eius divinitatem transferebat, ut eam patri consubstantialem negaret, quod et Philippus Melanchthon et Franciscus Davidis, Caspar Heltus et Matthias Hebler et similes faciunt; nam quae humanitatis Christi sunt, ad eius divinitatis iniuriam transferunt.

$<$ Melanchthonis et Francisci Davidis et reliquorum Saxonum haeresis longe superat haeresim Arrii.> Verum cum Arrii et Arrianorum haeresis omnibus aliis haeresibus pestilentior sit et perniciosior, tamen haec, quam praedicti Philippus Melanchthon scilicet et Franciscus Davidis et similes profitentur, haeresim Arrii in blasphemia longe superat. Nam Arrius parcebat illi maiestati paternae; isti vero minime! Cum enim concedant Philippus Melanchthon et sequaces filium dei ||[A10r.] esse aequalem et consubstantialem patri secundum divinitatem, et divinitas eius sit eiusdem substantiae indivisibilis cum patre et spiritu sancto, cunque divinitati filii illa humana opera tribuant, sequitur illos blasphemare non in filium tantum, sed et in patrem et spiritum sanctum deum trinum et unum, quia patris et filii et spiritus sancti una est divinitas, aequalis gloria, coaeterna maiestas.

$<$ Melanchthonis et sequacium haeresis composita ex antiqua, scilicet arriana, et nova inaudita, quae omnibus aliis haeresibus perniciosior est.> Quare non solum ecclesia catholica per totum orbem terrarum diffussa ex verbo dei, verum etiam ipse Arrius condemnant Melanchthonem, Casparum Heltum, Franciscum Davidis et superbum Matthiam Hebler, Cibiniensem Plebanum, cum similibus horribilis blasphemię et inauditae haereseos in totam sanctam trinitatem patrem, filium et spiritum sanctum, unum impartibilem deum. Nam quatenus $^{143}$ isti Saxones mini- $\mid[[$ A10v. $]$ stri - non Christi, sed Antichristi - dicunt Christum dominum secundum divinitatem orare, supplicare, mediare, obedire, gloriam postulare, cum Arrio et Arrianis plane conveniunt; et sic Arriani sunt et per consequens condemnati. Quatenus vero volunt Christum secundum divinitatem aequalem et consubstantialem esse (sicuti re vera est) patri et talia opera facere secundum eandem divinitatem, quam cum patre et spiritu

141. „uti“ bedeutet hier „wie“.

142. In der Vorlage: veo.

143. In der Vorlage: quatemus. 
sancto communem habet, nova blasphemia et nova haeresis est in unum deum, trinitatem, quamvis haec blasphemia et nova et inaudita haeresis Manichaicam et Donatistarum haeresim utcunque redoleat.

<Tomo 4 columna 160. 161. 162. 163.> Non aliter Nestorius haereticus sicuti Arrius condemnat reliquos Saxones ministros illius blasphemiae, ut apud divum Cyrillum legimus in apologetico anathematismo 10.

\section{ANHANG: DIE VON STANCARO BENUTZTEN QUELLEN}

Stancaro bezieht sich in seiner Synopse und Argumentation auf zahlreiche Schriften. Ich habe etliche der von ihm jeweils benutzten Ausgaben ermittelt und gebe sie hier in alphabetischer Reihenfolge der Autorennamen an; bei mehreren Werken eines Autors sind auch diese Werktitel alphabetisch geordnet.

\section{Augustin:}

- [Pseudo-Augustin:] „Contra Felicianum Arrianum“: Dieses Werk wird heute nicht mehr Augustin, sondern Vigilius von Thapsus zugeschrieben: „Mit großer Wahrscheinlichkeit darf der „Contra Felicianum Arianum de unitate trinitatis ad Optatum liber" als Werk des Vigilius gelten, ein Streitgespräch zwischen Felicianus und Augustin, wobei dieser sich in der Einleitung als Autor gibt, was zum Anlass wurde, die Schrift unter seine Werke aufzunehmen. “144 Es ist unter dem Titel „Divi Aurelii Augustini Hipponensis episcopi, contra Felicianum Arrianum, De unitate trinitatis ad Optatum liber" in der oben unter Punkt V.1. schon erwähnten Augustin-Ausgabe aus dem Jahr 1542 sowie in der Ausgabe von 1556 abgedruckt worden, und zwar in Bd. 6, Sp. 774-791. - Stancaro bezieht sich auf dieses Werk in der Marginalie seiner Schrift auf f. A8r., wo er die folgende Stelle angibt: „D. Augustinus tom. 6 contra Felicianum Arrianum cap. 13, columna 786“.

- „In Iohannis evangelium tractatus 124“: Stancaro bezieht sich auf f. A4v. seiner Schrift auf dieses Werk, und zwar auf den Tractatus 105: „Sic et alii

144. Martin Schanz, Geschichte der römischen Literatur bis zum Gesetzgebungswerk des Kaisers Justinian, Teil 4, Bd. 2: Die Literatur des fünften und sechsten Jahrhunderts, München $1959,569$. 
patres ut d. Augustinus tractatu in Ioannem 105“. Diese Stelle hat Stancaro vermutlich ebenfalls in der erwähnten Augustin-Ausgabe Basel 1542 (oder 1556) eingesehen. In dieser Edition sind die Traktate Augustins zum Johannesevangelium in Band 9 zu finden. Ein Exemplar dieses Bandes konnte ich jedoch leider nicht einsehen.

- „Sermo Arrianorum“: Siehe dazu schon oben unter Punkt V.1., wo die von Stancaro benutzte Ausgabe angegeben ist. Der „Sermo“ stammt nicht von Augustin, bildet aber die Grundlage für Augustins Widerlegung „Contra sermonem Arrianorum“ und wird deshalb in den Ausgaben jeweils mit ihr zusammen publiziert.

\section{[Pseudo-]Basilius von Cäsarea:}

- „Contra Eunomium“: Damit bezieht Stancaro sich auf die Schrift

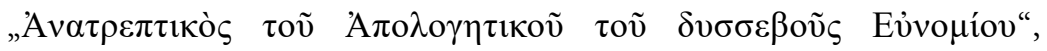
mit dem lateinischen Titel: „Adversus Eunomium“. In der Forschung wurde vermutet, dass dieses Werk ursprünglich nur auf drei Bücher angelegt war und die Bücher 4 und 5 später von Basilius angehängt wurden; jedoch wurde die Echtheit der zwei letzten Bücher in Zweifel gezogen, ${ }^{145}$ so dass heute deren Autor als „Pseudo-Basilius“ bezeichnet wird, zumal die Verfasserschaft nicht entschieden ist: Infrage kommen Basilius von Cäsarea, Didymus von Alexandrien und Apollinarius von Laodicea. ${ }^{146}$ Stancaro zog die Edition von Wolfgang Musculus heran: „Opera d. Basilii Magni Caesariae Cappadociae episcopi omnia, sive recens versa, sive ad Graecos archetypos ita collata per Wolfgangum Musculum Dusanum ut aliam omnino faciem sumpsisse videantur", Basel, Johannes Herwagen d.Ä., 1540 (VD 16 B 643). - Er verweist auf f. A4v. seiner Schrift auf Buch 4 dieses Werks, und zwar bezieht er sich auf die Seite 175 der genannten Ausgabe; die Abschnitte, die Stancaro meint, stehen dort unter den Überschriften „Super illo verbo, Pater glorifica me“ und „Super eodem“.

145. Siehe dazu Paulys Realencyclopädie der classischen Altertumwissenschaft. Neue Bearbeitung, hg. v. Georg Wissowa, 5. Halbbd., Stuttgart 1897, Sp. 54.

146. Siehe Franz Xaver Risch, Pseudo-Basilius Adversus Eunomium IV-V. Einleitung, Übersetzung und Kommentar, Leiden, New York, Köln 1992, 3. 


\section{Bucer, Martin:}

- „Enarratio in evangelion Iohannis, Praefatio, summam disputationis et reformationis Bern[ensis] complectens“, Straßburg 1528 (VD 16 B 8870). Das Kapitel 17 beginnt darin auf f. 237. Stancaro verweist darauf auf f. A4v. seiner Schrift.

\section{Cyrill von Alexandria:}

- „Ad reginas de recta fide liber” (ausführlicher Titel: „Divi Cyrilli archiepiscopi Alexandrini ad pientissimas reginas de recta in dominum nostrum Iesum Christum fide liber"). Cyrill wandte sich mit dieser Schrift an Arkadia und Marina, zwei Schwestern des Kaisers Theodosius II. (geb. 401, gest. 450). Es handelt sich dabei um eine "Sammlung von Schrift- und Vätertestimonien. “ 147 Stancaro zog dafür nachweislich die folgende vierbändige Ausgabe heran: „Operum divi Cyrilli Alexandrini episcopi tomi quatuor, quorum postremus nunc recens accedit, ex graecis manuscriptis exemplaribus fideliter latinitate donatus“, Basel, Johannes Herwagen, 1546 (VD 16 C 6568; C 4202; N 550). Das Buch „Ad reginas de recta fide", auf das Stancaro sich in seiner Schrift bezieht, steht dort in Band 3 auf Sp. 282-337. ${ }^{148}$ - Stancaro verweist auf f. A1v. seiner Schrift auf dieses Werk: „D[ivus] Cyril[lus] tomo 3 ad reginas columna 331“.

- „Ad reginas de recta fide liber alius“ (ausführlicher Titel: „Divi Cyrilli archiepiscopi Alexandrini, ad pientissimas reginas de recta in dominum nostrum Iesum Christum fide liber alius"). Cyrill richtete diese Schrift an Pulcheria (die dritte Schwester des Kaisers Theodosius II.) sowie an die Gattin des Kaisers, Ailia Eudokia (Athenais). Diese Abhandlung ist mit der ersten, oben genannten Schrift eng verbunden. In ihr wird der Lehrgehalt der Testimonien dargelegt. - Stancaro hat sich zweimal auf f. A5v. seiner Schrift auf dieses Werk Cyrills bezogen. Die erste Stelle lautet bei Stancaro: „Cyril-

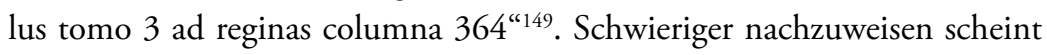
die zweite Erwähnung auf f. A5v., in der Stancaro schreibt: „Cyrillus tomo

147. Siehe Edward R. Hardy, „Cyrillus von Alexandrien“, in: Theologische Realenzyklopädie, Bd. 8, Berlin, New York 1981, 257.

148. Gedruckt ist diese Schrift Cyrills beispielsweise auch in der „Patrologia Graeca“ von Jacques Paul Migne (PG, Bd. 76 = Cyrill, Werke, Bd. 9, Paris 1859), nämlich auf Sp. 1201-1336.

149. In dem Bd. der oben schon erwähnten Cyrill-Ausgabe (VD 16 C 6568), der in VD 16 online einsehbar ist - München BSB 133924852 P.gr. 129-1/4 - ist die Reihenfolge der Lagen nicht ganz korrekt, denn die Sp. 364 und 365 folgen erst nach den Sp. 366 und 367 (letztes Abrufdatum: 14.06.2018). 
4 ad reginas columna $366^{\prime \prime}$. Der Band 4 kann keinesfalls gemeint sein. Es handelt sich vielmehr um einen Druckfehler - gemeint ist der eben schon erwähnte Band 3 der Cyrill-Ausgabe (VD 16 C 6568), in dem das Buch „Ad reginas de recta fide liber alius“ auf Sp. 338-373 zu finden ist.

- „In Ioannem“: Es handelt sich um Cyrills Kommentar zum Johannes-Evangelium. Der vollständige Titel lautet in der von Stancaro benutzten, oben schon erwähnten vierbändigen Basler Ausgabe von 1546, Band 1 (Inhaltsverzeichnis dort auf f. A3r.): „Divi Cyrilli Alexandrini in Evangelium Ioannis commentariorum libri VIII. Quibus Iodocus Clithoveus [= Josse Clicthove] adiecit quatuor inter medios". - Stancaro bezieht sich mehrmals auf dieses Werk: Auf f. A4r. verweist er auf Buch 9, Kapitel 42, Sp. 471, sowie auf Buch 2, Kapitel 92, Sp. 106. Auf f. A4v. verweist er auf Buch 11, Kapitel 17, Sp. 545, sowie auf Buch 11, Kapitel 18, Sp. 547.

- „Liber apologeticus“: Gemeint ist hiermit Cyrills „Liber apologeticus pro duodecim capitulis ad orientales episcopos, qui illa scriptis taxarant“, der sich in Band 4 der vierbändigen Basler Cyrill-Ausgabe von 1546 befindet (dort in Sp. 142-187). In der Marginalie von Stancaros Schrift sind die Stellen für den „Anathematismus X“ im „Liber apologeticus“ in Band 4 genau angegeben: Sp. 160-163. - Stancaro bezieht sich auf f. A10v. seiner Schrift auf dieses Werk und erwähnt in diesem Zusammenhang auch Nestorius. Dieser war ab 428 Bischof von Konstantinopel, betonte die Existenz zweier Naturen in Christus (Dyophysitismus) gegenüber der alexandrinischen Theologie und wurde auf Betreiben Cyrills von Alexandrien auf dem Konzil von Ephesus (431) verurteilt und verbannt. ${ }^{150}$

- „Liber Thesauri“ (oder auch: „Thesaurus adversus haereticos“): Der vollständige Titel lautet in der von Stancaro benutzten, oben schon erwähnten vierbändigen Basler Ausgabe von 1546: „Opus insigne quod Thesaurus inscribitur, de consubstantialitate filii et spiritus sancti cum deo patre, adversus haereticos". - Stancaro bezieht sich auf f. A4v. seiner Schrift auf Band 2 der Cyrill-Ausgabe, der den „Thesaurus“ enthält: Bd. 2, Buch 10, Kapitel 2 mit dem Inzipit „Non quod gloria“, Sp. 116 und 117; Bd. 2, Buch 10, Kapitel 9 mit dem Inzipit „Sed quomodo“, Sp. 133. 


\section{Davidis, Franz (Dávid Ferenc):}

- „Apologia adversus maledicentiam et calumnias Francisici Stancari“: Der Titel lautet vollständig: „Apologia adversus maledicentiam et calumnias Francisici Stancari, iussu et voluntate omnium docentium coelestem doctrinam incorrupte in ecclesiis Transylvanicis conscripta. Per ministros ecclesiae Claudiopolitanae in eadem Transylvania“, Claudiopoli (Koloszvár, Klausenburg, Cluj), Georg Hoffgreff, 1558. ${ }^{151}$ Zur Vorgeschichte dieser Schrift ist anzumerken, dass es im Jahr 1557 zu einem Streitgespräch zwischen Franz Davidis und Kaspar Helt auf der einen und Stancaro auf der anderen Seite gekommen war, bei dem erste Anzeichen zutage traten, dass Stancaro zum Nestorianismus neigte. ${ }^{152}$ - Stancaro hat allerdings in seiner Schrift die Titel der gegen ihn gerichteten Streitschriften von Franz Davidis und Kaspar Helt nicht explizit angegeben, sondern auf f. A2r. nur zusammenfassend erwähnt: „in scriptis Francisci Davidis et Helti“.

- „Dialysis scripti Stancari“: Der Titel lautet vollständig: „Dialysis scripti Stancari contra primum articulum synodi Szekiensis, qui de doctrina controvertitur, conscripta per Franciscum Davidis“, Claudiopoli, Georg Hoffgreff, 1555. Im Jahr 1555 wandte sich Franz Davidis im Auftrag der lutherischen Gemeinde von Klausenburg mit dieser Schrift gegen Stancaro. ${ }^{153}$

Epiphanius aus Judäa, Bischof von Konstantia (Salamis) auf Zypern ${ }^{154}$ :

- „Panarium“ (griechisch: „Паvóptov“; lateinisch auch: „Contra haereses“ oder nur: „Haereses“). Dieser Text stand zu jener Zeit in der folgenden Ausgabe zur Verfügung: „D. Epiphanii episcopi Constantiae Cypri, contra octoaginta[!] haereses opus, Panarium, sive Arcula, aut Capsula Medica appellatum, continens libros tres, et tomos sive sectiones ex toto septem. Iano Cornario medico physico interprete [...]", Basel, Robert Winter, 1545 (VD 16 E 1645). - Stancaro hat sich in zwei Marginalien auff. A8r. seiner Schrift

151. Siehe Gedeon Borsa, Alte siebenbürgische Drucke (16. Jahrhundert), Köln, Weimar, Wien 1996, 112f., Nr. 106.

152. Siehe Bernhard, Konsolidierung (wie Anm. 7), 289, Anm. 15.

153. Siehe Hein, Italienische Protestanten (wie Anm. 72), 82, Anm. 77. - Das einzig erhaltene Exemplar befand sich im Jahr 1964 im Budapester Nationalmuseum; siehe Roth, Reformation in Siebenbürgen (wie Anm. 7), 21, Anm. 5. - Siehe auch Borsa, Drucke (wie Anm. 151), 94f., Nr. 88. 154. Geb. um 315, gest. 403. 
auf mehrere Seiten dieser Ausgabe bezogen (auf die S. 353. 370. 371. 476. 489) und in einer Marginalie auf f. A8r. auf „Epiph. pag. 353“.

\section{Helt, Kaspar („Caspar Heltus"):}

- „Confessio de mediatore generis humani Jesu Christo, vero deo et homine“: Diese Schrift von Helt, die vielleicht handschriftlich blieb, ${ }^{155}$ stammt aus dem Jahr 1555 und gehört zu den Streitschriften, mit denen die siebenbürgischen Protestanten den Lehren Stancaros entgegenzutreten versuchten. ${ }^{156}$ Bereits 1554 hatten sie ihre Übereinstimmung mit Melanchthon bekräftigt und in der Honterus-Wagnerischen Druckerei in Kronstadt Melanchthons „Responsio de controversiis Stancari“ herausgegeben. ${ }^{157}$ - Stancaro bezieht sich im weiteren Sinne mit seiner ganzen Schrift auf Helt (im Titel der „Collatio“ ist Helt unter den „reliqui Saxones“ mit zu verstehen), nennt ihn aber explizit mit Namen auf f. A2r., A6v., A9v. und A10r., stets in Zusammenhang mit Franz Davidis und den anderen siebenbürgischen Theologen.

\section{Luther, Martin:}

- „De novissimis verbis Davidis“: Es handelt sich um die Schrift „De novissimis verbis Davidis commentatio pia et sancta Martini Lutheri, theologiae doctoris, Germanice explicata ab autore et in Latinum sermonem conversa, studio et diligentia Caspari Crucigeri, d. theologiae, nunc primum seorsim edita“, Leipzig, Valentin Bapst, 1550 (VD 16 L 7166). - Stancaro erwähnt sie auf f. A6v. seiner Schrift: „vide Lutterum de Novissimis verbis Davidis prophetae, pagina 109 et 132 “.

Es gibt zwei weitere Stellen, in denen sich Stancaro auf Luther bezieht:

- Die erste Stelle befindet sich auf f. A4v. seiner Schrift und lautet: „Filius dei haereditatem gentium et regnum a patre petit sibi dari [...] Lutterus in Psalmum tomo 2“. Dabei meint Stancaro den Band 2 der Jenaer Luther-Gesamtausgabe von Christian Rödinger (Rhodius), erschienen im Jahr 1557 (VD 16 L 3424), in dem sich die „Operationes in Psalmos“ befinden und wo un-

155. Siehe Borsa, Drucke (wie Anm. 151), 386f., Nr. App. 9.

156. Siehe Roth, Reformation in Siebenbürgen (wie Anm. 7), 21, Anm. 5.

157. Responsio Philippi Melantho[!], de controversiis Stancari. Scripta anno MDLIII, [Brassó (Brasov, Kronstadt): Wagner], 1554. Siehe Borsa, Drucke (wie Anm. 151), 70, Nr. 64; Gustav Gündisch, Karl Reinerth, Melanchthon und die Spaltung im siebenbürgischen Protestantismus, in: Zeitschrift für siebenbürgische Landeskunde, IV. Folge, 2/1 (1979), 2 mit Anm. 7. 
ter dem Vers 2, 8 (auf f. 14v.-15r.) zu lesen ist: „Dixit, inquit, dominus ad me mandavitque mihi pater, ut postulem ab eo gentes in haereditatem “. ${ }^{158}$

- Die zweite Stelle befindet sich auf f. A5r. von Stancaros Schrift und lautet: „Filius dei haereditatem gentium et regnum a deo patre sibi dari petit et orat: et inde concludit filium dei secundum divinitatem etiam ante incarnationem orasse. Quod argumentum etiam arripuit (ut Lutterus quoque ait in Psal. 2.) Arrius contra divinitatem Christi“. Es kann sich hier nicht wie oben um Band 2 der Jenaer Ausgabe von Luthers Werken handeln, weil dort nicht die eben zitierte Aussage über Arius zu finden ist. Hier ist vielmehr die zum ersten Mal von Veit Deitrich in Wittenberg im Jahr 1546 herausgegebene „Enarratio Psalmi secundi“ (Wittenberg, Hans Lufft, 1546; VD 16 L 4540) gemeint, die auch im 4. Band (erschienen 1558) der Jenaer Ausgabe (VD 16 3427) nachgedruckt wurde. In diesem Nachdruck ist unter dem Psalm 2, 8 („Postula a me, et dabo tibi gentes“) auf f. 767r. zu lesen: „Haec simul ad regni et personae descriptionem referenda sunt. Arripuit Arius quoque hunc locum contra divinitatem. ${ }^{\text {159 }}$

\section{Melanchthon, Philipp:}

- „Confessio Augustana“ (kurz: CA; das Augsburger Bekenntnis) und „Apologie der Confessio Augustana“" (kurz: AC; die Verteidigungsschrift der Confessio Augustana): Zunächst erwähnt Stancaro auf f. A6v. seiner Schrift die „Confessio Augustana” und bezieht sich auf deren ersten Artikel, in dem unter anderem der Arianismus als häretisch verworfen wird. ${ }^{160}$ Die „Confessio Augustana" lag in sehr vielen Ausgaben vor (vgl. etwa die Einträge in VD 16), so dass hier unmöglich entschieden werden kann, welche von ihnen Stancaro besaß bzw. hier benutzt hat. Es muss zudem bedacht werden, dass Stancaro den Inhalt der CA sicherlich sehr gut kannte und sich auch aus dem Gedächtnis darauf berufen konnte. Auf f. A7r. schreibt er dann Folgendes: ,idem facit Philippus Melanchton in apologia praefatae confessionis in 1 articulum [...]". Damit bezieht Stancaro sich zunächst auf Artikel 1 von Melanchthons „Apologie der Confessio Augustana“, also auf Melanch-

158. In der Weimarer Ausgabe (WA) ist diese Stelle gedruckt in Bd. 5, 61.

159. In der Weimarer Ausgabe (WA) ist diese Stelle gedruckt in Bd. 40/2, 260.

160. Siehe etwa die neueste Edition: Die Bekenntnisschriften der Evangelisch-Lutherischen Kirche. Vollständige Neuedition, hg. v. Irene Dingel im Auftrag der Evangelischen Kirche in Deutschland, Göttingen, Bristol, CT, 2014, $94 \mathrm{f}$. 
thons umfangreiche Verteidigung des Augsburger Bekenntnisses, mit der er sich gegen die „Confutatio Augustanae Confessionis“ (Widerlegung des Augsburger Bekenntnisses) der Katholiken richtete. Die „Apologie“ wurde am 3. August 1530 vor den auf dem Reichstag zu Augsburg versammelten Ständen verlesen. In ihrem ersten Artikel bestätigen die Lutheraner, dass die „widdersacher" - gemeint sind die Katholiken - den ersten Artikel der „Confessio Augustana“ (mit der Lehre der Lutheraner über Gott, Sohn und den Heiligen Geist) billigen. ${ }^{161}$ Die Apologie des Augsburger Bekenntnisses wurde häufig zusammen mit dem Augsburger Bekenntnis gedruckt, so dass hier keine bestimmte Ausgabe ermittelt werden kann. Vielleicht wird Stancaro auch ihren Text im Gedächtnis gehabt haben.

- „Definitiones multarum appellationum, quarum in ecclesia usus est, traditae a Philippo Melanthone ${ }^{162}$ Torgae et Witebergae anno 1552 et 1553 “. Es existieren etliche Ausgaben dieser Schrift. ${ }^{163}$ Sie wurde zunächst nicht separat gedruckt, sondern an Melanchthons „Loci praecipui theologici“ - das ist ein späterer Titel der berühmten „Loci communes“ - angehängt (Leipzig, Valentin Bapst d. Ä., 1553, VD 16 M 3654; Melanchthon-Bibliographie III 1716f., Nr. 1553.37). Erst im Jahr 1554 wurden die „Definitiones“ auch einzeln in Wittenberg gedruckt (VD 16 M 2929; ZV 148). Sie wurden zudem 1555 in "Coronae" (Brassó, Kronstadt, Braşov) nachgedruckt. ${ }^{164}$ Überdies brachte man im Verlauf des Jahres 1559 (in welchem Monat?) ${ }^{165}$ Melanchthons „Responsio de controversia ${ }^{166}$ Stancari“ zusammen mit den „Definitiones multarum appellationum [...] traditae a Philippo Melanth. Torgae et Vuitebergae“ innerhalb einer Ausgabe von Melanchthons „Examen ordinandorum" heraus (Wittenberg, Lorenz Schwenck, 1559; VD 16 M 3931; Melanchthon-Bibliographie III 2241, Nr. 1559.116). Hatte vielleicht Stancaro die „Definitiones“ Melanchthons erst aus dieser Ausgabe kennengelernt, oder war seine „Collatio“ schon früher ganz fertig geschrieben, ehe er im Mai 1559 nach Pińczów kam? Wie dem auch sei, bezieht sich

161. Siehe ebd., $244 f$.

162. Die Namensform „Melanthon“ hat Philipp Melanchthon ab dem Jahr 1531 selbst verwendet; siehe Heinz Scheible, Melanchthon. Eine Biographie, München 1997, 16.

163. Sie sind in VD 16 verzeichnet. Neuere Ausgabe in: CR 21, Sp. 1075-1106.

164. Siehe Borsa, Drucke (wie Anm. 151), 86f., Nr. 79.

165. Über das genaue Erscheinungsdatum bzw. über die Datierung einer etwaigen Vorrede in dieser Ausgabe konnte nichts ermittelt werden.

166. Im Unterschied zum sonstigen Titel: „Responsio de controversiis Stancari“. 
Stancaro mit den Worten „in libro dictato in Torgae“ (auf f. A2r.) gewiss auf die „Definitiones“, über die Melanchthon 1552 und 1553 in Torgau und Wittenberg gelesen hatte. ${ }^{167}$ - Stancaro nimmt in seiner "Collatio“ auf den Abschnitt „Filius“ der „Definitiones“ Bezug, wo die Eigenschaften des Gottessohnes beschrieben werden (siehe etwa den Textabdruck in CR 21, Sp. 1077).

- „Epistola ad electorem Brandeburgensem“: Solch einen Brief Melanchthons an den Kurfürsten Joachim II. von Brandenburg erwähnt Stancaro zweimal auf f. A2r. und je einmal auf f. A3r. und A6r. seiner Schrift. Hier muss aber zunächst noch vorausgeschickt werden, dass es von Melanchthon in Bezug auf Stancaro insgesamt drei Briefe an den Kurfürsten von Brandenburg gibt: 1) ein deutsches Schreiben vom 3. Oktober 1552 (MBW, Regesten, Bd. 6, S. 354f., Nr. 6580, und CR 7, 1086-1088, Nr. 5215), 2) ein weiteres deutsches Schreiben vom 12. Januar 1553 (MBW, Regesten, Bd. 7, S. 23, Nr. 6706, und CR 8, 16-18, Nr. 5313), und schließlich 3) das oben schon kurz erwähnte, lateinische Gutachten an den Kurfürsten unter dem Titel „Responsio de controversia [oder: controversiis] Stancari“, das gleichfalls als Brief an den Kurfürsten verfasst wurde und zu dem weiter unten der Haupteintrag zu finden ist. Da aber Stancaro die „Responsio“ schon auf f. A2r. seiner Schrift erwähnt, kann hier nur einer von den beiden zuerst genannten Briefen infrage kommen, also der Brief vom 3. Oktober 1552 oder der vom 12. Januar 1553.

Auf f. A5r. verweist Stancaro auf die „Epistola ad electorem Brandeburgensem scripta ianuarii 12. anno 1553“ und auf f. A6r. auf die „Epistola ad electorem scripta Torgae 3. octobris 1552“. Bei den oben aufgezählten Verweisen, die das Datum der „Epistola“ nicht anführen, kann also nur der Kontext die Lösung bringen.

Im Brief vom 3. Oktober 1552 äußert Melanchthon seine Bedenken gegenüber der geplanten Abhaltung einer Disputation in Berlin zwischen Stancaro und Andreas Musculus, zu der es am 10. Oktober auch kam. ${ }^{168}$ Eine solche Konfrontation könne nur noch größere Unruhen stiften. Danach widersetzt sich Melanchthon Stancaros Behauptung, laut der Chris-

167. Siehe Karl Hartfelder, Melanchthon als Praeceptor Germaniae, Berlin 1889 (Reprint 1964), 564 (wo zudem bemerkt wird, dass die „Definitiones“ vielleicht im Kontext einer am 19. November 1552 gehaltenen Vorlesung zur „Doctrina de mediatore“ gegen Stancaro vorkamen).

168. Siehe dazu Hein, Italienische Protestanten (wie Anm. 72), 78-80. 
tus nur als Mensch Vermittler sei. Für Melanchthon ist Christus in seinen beiden Naturen Vermittler, da zu den Eigenschaften des Vermittlers „nicht allein das Leiden, sondern auch der Sieg und die Fürbitte" gehören. In seiner göttlichen Natur hat Christus Anteil am göttlichen heimlichen Plan, wirkt zudem als Hohepriester und kann Gottes Zorn gegen die Sünde besänftigen und für uns Fürbitte einlegen.

In seinem Brief vom 12. Januar 1553 erwähnt Melanchthon die ihm zugeschickten Thesen, die Stancaro und Musculus während der Disputation in Berlin verteidigt hatten. Danach bedauert er derartige Streitereien, die nur zerstörend seien. Er empfiehlt, sich vielmehr an die Aussagen gegen die Nestorianer des ersten Konzils von Ephesus (431 n. Chr.) zu halten. Dann kommt er auf Christi Amt als Mittler zu sprechen: Laut dem Hebräerbrief, der sich auf Psalm 2, 7f. bezieht, übt Christus dieses Amt als Gottessohn aus. Wäre das nicht der Fall, wozu sollte dann seine göttliche Natur dienen? Dass diese eine wichtige Rolle spielt, gehe aus Christi Gebet hervor, in dem er den Vater darum bittet, ihn zu verherrlichen und ihm den Glanz wieder zurückzugeben, den er vor der Erschaffung der Welt hatte (Joh 17, 5). Abschließend bedauert Melanchthon, dass Stancaro ihn so grausam verleumdet.

Demzufolge beziehen sich die zwei Verweise auf f. A2r. und derjenige auf $f$. A6r. auf Melanchthons Brief vom 3. Oktober 1552, und der Verweis auf $f$. A3r. auf den Brief vom 12. Januar 1553.

- „Responsio de controversiis Stancari“ (Leipzig, Valentin Bapst d. Ä., 1553, VD 16 M 4140; Melanchthon-Bibliographie III 1717, Nr. 1553.38), die Melanchthon am 24. Juni 1553 in Dessau als Gutachten an Kurfürst Joachim II. von Brandenburg adressierte (siehe das Regest auf Deutsch in: MBW, Regesten, Bd. 7, S. 78, Nr. 6854). ${ }^{169}$ Diese Schrift wurde zusammen mit den „Definitiones“ von Melanchthon 1559 in Wittenberg erneut nachgedruckt (siehe schon oben). Es kam 1559 auch zu einer Publikation der „Responsio“ durch den Drucker Daniel aus Lenschitz in Pińczów (siehe Melanchthon-Bibliographie III 2196f., Nr. 1559.53). - Spätere Ausgaben: CR 23, Sp. 87-102 (stark veränderte Fassung); Melanchthons Werke in Auswahl. Studienausgabe, hg. von Robert Stupperich, Bd. 6: Bekenntnisse

169. Zu Melanchthons „Responsio“ siehe etwa Carl Schmidt, Philipp Melanchthon. Leben und ausgewählte Schriften, Elberfeld 1861, 566-569. 
und kleine Lehrschriften, Gütersloh 1955, S. 260-277. - Stancaro bezeichnet dieses Buch mit den folgenden Worten: „in libello de controversiis Stancari edito“ bzw. „in libro contra Stancarum edito“ auf f. A2r. und erwähnt es auch danach noch auf $\mathrm{f}$. A3r., A5r. und A6r.

- „Loci communes“: Dies ist Melanchthons berühmtes dogmatisches Werk über die theologischen Grundbegriffe, das im Jahr 1521 erstmals erschien und später noch mehrmals überarbeitet wurde. Hier kommen angesichts von Stancaros Seitenangaben verschiedene Ausgaben infrage, denen jedoch der Druckort Basel gemeinsam ist: ${ }^{170}$ die Editionen Basel, Robert Winter, 1545 (VD 16 M 3640) und 1546 (VD 16 M 3642); die Editionen Basel, Johannes Oporin, 1555 (VD 16 M 3656) und 1558 (VD 16 M 3660). In diesen Drucken finden sich im Kapitel „De filio“ auf S. 40 unter den „Testimonia“ im Abschnitt „Convenit autem“ die entsprechenden Verben erwähnt („ut obediret Deo in passione [...], sed se ipsum exinanivit, id est, non exeruit potentiam suam, et humiliavit se formam servi acciepiens [...]"), auf die Stancaro sich auf f. A3r. („,in suis locis communibus, pagina 40“) und A6r. („ut in suis locis communibus pagina 40“) seiner Schrift bezieht. Ein weiterer Bezug auf Melanchthons „Loci communes“ findet sich auf $f$. A5r. (,in suis locis communibus pagina 43“). - Lorenz Hein hat bemerkt, dass Stancaro „entsprechend seiner polemischen Zielsetzung sinnentstellend den Zusammenhang “ zerreiße. $^{171}$

- „Epistola ad Romanos“: Stancaro verweist auf f. A7r. seiner Schrift auf Melanchthons Kommentar zum Brief des Apostels Paulus an die Römer. Dabei bezieht er sich auf eine Verketzerung von Arius durch Melanchthon, die sich seiner Äußerung nach im Kapitel 14 auf S. 360 von Melanchthons Römerkommentar befinden soll. Die von ihm benutzte Ausgabe gibt er jedoch nicht an. Melanchthon hat sich über Jahrzehnte hinweg mit dem Römerbrief beschäftigt und diverse Kommentare dazu publiziert. ${ }^{172}$ Daher gilt es herauszufinden, in welcher Ausgabe eines Römerbriefkommentars von Melanchthon Arius im 14. Kapitel auf S. 360 verketzert wird. Die in

170. Geprüft wurde dies durch einen Vergleich der Volltexte, die in der elektronischen Ausgabe von VD 16 verfügbar sind.

171. Hein, Italienische Protestanten (wie Anm. 72), 98, Anm. 120.

172. Siehe dazu Melanchthons Werke, 5. Bd.: Römerbrief-Kommentar 1532, in Verbindung mit Gerhard Ebeling hg. v. Rolf Schäfer, Gütersloh 1965, 15-24 (Einleitung). 
CR 15 abgedruckten Arbeiten Melanchthons zum Römerbrief erlauben eine Antwort darauf. Es zeigt sich, dass folgender Abschnitt gemeint sein muss: „Anno domini 324 Nicena synodus a Constantino convocata est, in qua praefuit Antiochenus Episcopus Eustathius. In hac synodo gravissimae controversiae dogmatum diiudicatae sunt, et recte damnati sunt errores Samosateni et Arii. Item Catharorum, qui lapsos renegabant recipiendos esse, ac negabant eos consequi remissionem peccatorum. "Dieser Abschnitt steht in Kapitel 14 von Melanchthons „Commentarii in epist. Pauli ad Romanos“ (CR 15, Sp. 493-796, hier Sp. 744), der zunächst in einer einfacheren Form in Wittenberg bei Joseph Klug im Jahr 1532 erschienen war $^{173}$, in dem allerdings der eben zitierte Auszug noch nicht vorhanden ist. Dieser wurde erst in der erweiterten Ausgabe publiziert, die im März 1540 in Straßburg von Kraft Müller (Crato Mylius) veranstaltet wurde - und zwar innerhalb einer zusätzlichen Schrift Melanchthons aus dem Jahr 1539, die „De ecclesiae autoritate et de veterum scriptis libellus ${ }^{\text {“174 }}$, die diesem Römerbriefkommentar einverleibt wurde. In der Onlineversion von VD 16 können von dem Straßburger Druck von März 1540 unter der Nummer VD 16 M 2743 zwei Exemplare (aus der Thüringischen Universitäts- und Landesbibliothek Jena und aus der Universitäts- und Landesbibliothek Sachsen-Anhalt Halle/ Saale) eingesehen werden. Beide weisen unsere Stelle auf der Seite 360 auf (die Schrift „De ecclesiae autoritate“ beginnt dort auf S. 338). Das wird also die Auflage sein, die Stancaro in seiner „Collatio“ benutzt hat. Es muss noch darauf hingewiesen werden, dass es wenige Monate später, im September 1540, zu einem Nachdruck von Melanchthons Römerkommentar durch Kraft Müller kam, ${ }^{175}$ bei dem unsere Stelle jedoch auf S. 504 steht. Dieser Nachdruck kann hier also nicht gemeint sein. Auch die Wittenberger Edition von Josef Klug aus dem Jahr 1540/41 176 kommt nicht infrage, obwohl dort (auf f. CCLXIIIIv.) das Kapitel 14 mit einer Kustode „De ec“ endet und somit auf der folgenden Seite den Text „De ecclesiae autoritate " erwarten lässt - aber auf der nächsten Seite geht es weiter mit Kapitel 15 des Römerbriefkommentars! Dies lässt sich damit erklären, dass

173. VD 16 M 2741; Melanchthon-Bibliographie I 459f., Nr. 1532.56. Siehe auch CR 15, 493f. (Vorspann).

174. VD 16 M 3081; Melanchthon-Bibliographie I 779f., Nr. 1539.79.1 und 1539.79.2.

175. VD 16 M 2744; Melanchthon-Bibliographie I 840, Nr. 1540.90.

176. VD 16 M 2745; Melanchthon-Bibliographie II 920, Nr. 1541.93 (siehe hier insbesondere den Vermerk am Ende des Eintrags). 
entweder noch Restexemplare von „De ecclesiae autoritate“ übrig waren, die Melanchthon in den Römerbriefkommentar von Josef Klug einbinden lassen wollte, dass aber heute nicht mehr alle Exemplare über diesen Einschub verfügen, weil die Restauflage seiner Schrift „De ecclesiae autoritate“ früher aufgebraucht war, oder weil der Käufer diesen Text zwar mitgeliefert bekam, aber nicht mit einbinden ließ. Ausgeschieden werden müssen hier auch nach entsprechender Prüfung die in VD 16 aufgenommenen und online einsehbaren späteren Drucke von Melanchthons Römerbriefkommentar, die ich bis zum Jahr 1559 eingesehen habe. Es lässt sich also festhalten, dass Stancaro Melanchthons Römerbriefkommentar in der Straßburger Ausgabe von Kraft Müller von März 1540 herangezogen hat.

\section{Stancaro, Francesco:}

Stancaro bezieht sich in seiner "Collatio doctrinae" auch auf eigene Bücher: Auf f. A5v. schreibt er: „Stancari de filio dei et libros eius contra novos Arrianos scriptos“. Auf f. A6r. schreibt er: „Vide librum Stancari”. Es ist nicht klar, welche Schriften damit gemeint sein können. In einem Brief an Georg Buchholzer vom 11. Februar 1552 aus Frankfurt gibt Stancaro zwar Auskunft über einige seiner Werke (von denen vielleicht manche auch ungedruckt geblieben sein mögen); darunter nennt er auch eine in Bearbeitung befindliche Schrift (gegen Osiander), in deren Mittelpunkt Christus steht: „[...] prae manibus habeo etiam contra Osiandrum, quo deus et Christus in nobis et nos in eo simus " 177 - aber kann dies als ausreichendes Indiz für die Annahme gelten, dass diese Schrift hier gemeint ist? Ältere Verzeichnisse von Werken Stancaros geben auch keinen Aufschluss auf eine Schrift „De filio dei“ oder „Contra novos Arrianos“ (geprüft habe ich dafür die Werkübersicht in der „Bibliotheca“ von Konrad Gessner aus dem Jahr $1583^{178}$ sowie Pierre Bayles Wörterbuch in der deutschen Ausgabe von Johann Christoph Gottsched von $1744^{179}$ ). Die beiden genannten Themen hat Stancaro zudem überwiegend in der vorliegenden Schrift behandelt, und seine nach 1559 publizierten Schriften kommen hier nicht infrage. Somit bleibt vorerst offen, worauf genau Stancaro sich hier bezogen hat.

177. Wotschke, Stancaro (wie Anm. 10), 602, unter Nr. VI.; siehe ferner ebd., 483 mit Anm. 4. 178. VD 16 G 1705.

179. Herrn Peter Baylens Historisches und Critisches Wörterbuch, nach der neuesten Auflage von 1740 ins Deutsche übersetzt [...] von Johann Christoph Gottscheden, Vierter und letzter Theil, $\mathrm{O}$ bis Z, Leipzig 1744, 282-286, bes. 284. 
Dr. phil. Judith Steiniger

Universität Zürich

Theologische Fakultät

Heinrich Bullinger-Briefwechseledition

Kirchgasse 9

CH-8001 Zürich

steiniger@theol.uzh.ch

\begin{abstract}
The editorial work on the extensive correspondence of the Zurich reformer Heinrich Bullinger provided new insights into the Italian religious refugee Francesco Stancaro and his stay in Basel towards the end of the Schmalkaldic War. In addition, the only surviving copy of Stancaro's Collatio doctrinae Arrii et Philippi Melanchthonis from 1559 was found in Zurich. In this tract Stancaro argued against Melanchthon and the Hungarian theologian Franz Davidis (Ferenc Dávid). Since this text is barely known today, it is edited here and put into the context of its printing history. The sources used by Stancaro are listed in the appendix.
\end{abstract}

